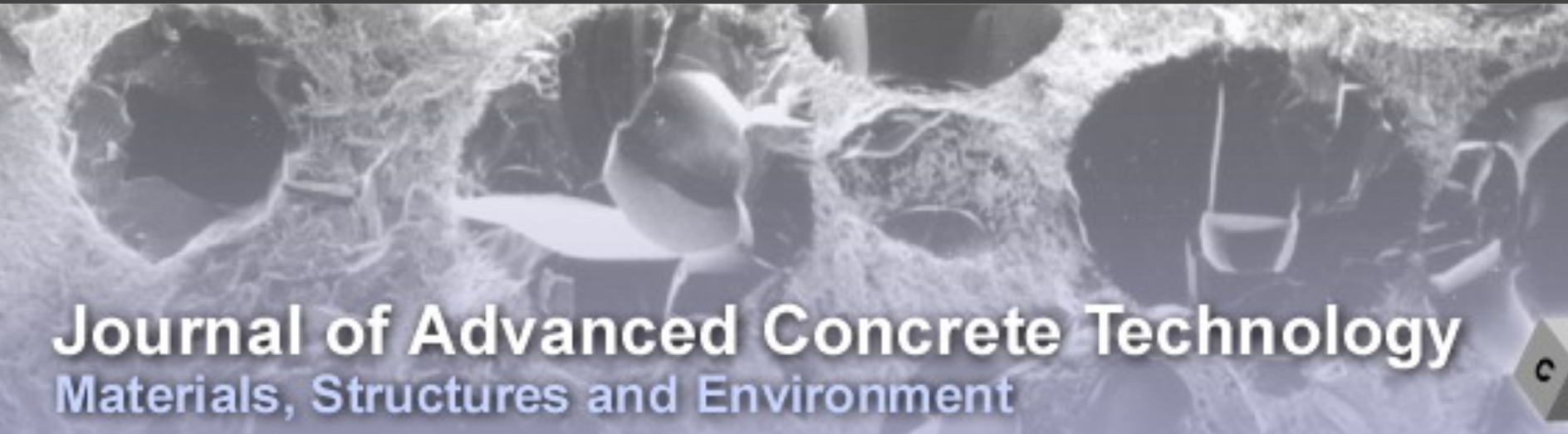

\title{
Investigation on the Pull-out Behavior of Deformed Bars in Cracked Reinforced Concrete
}

Koji Matsumoto, Tao Wang, Daisuke Hayashi, Kohei Nagai

Journal of Advanced Concrete Technology, volume 14 (2016 ), pp. 573-589

\section{Related Papers Click to Download full PDF!}

Mesoscopic Simulation of Failure of Mortar and Concrete by 2D RBSM

Kohei Nagai[YasuhikoSato[Tamon Ueda

Journal of Advanced Concrete Technology, volume 2 (2004), pp. 359-374

Shear Fatigue Response of Cracked Concrete Interface

Esayas GebreyouhannHN, Toshiharu Kishi, Koichi Maekawa

Journal of Advanced Concrete Technology, volume 6 (2008), pp. 365-376

Mesoscale 0 odelling of the \&hloride ' iffusion in \&racks and \&racked \&oncrete Licheng Wang, Tamon Ueda

Journal of Advanced Concrete Technology, volume 9 (2011), pp. 241-249

Application of X-ray CT to 6 tudy ' iffusivity in \&racked \&oncrete through the 2 bservation of 7 racer] 7 ransport

Ivan Sandi Darma, Takafumi Sugiyama, Michael[\$QJHQR]\% Promentilla

Journal of Advanced Concrete Technology, volume 11 (2013), pp. 266-281

Application of Sacrificial Point Anode for Prevention of Steel Corrosion in Cracked Concrete Muhammad \$NEDUCaronge, Hidenori Hamada, Rita Irmawaty, Yasutaka Sagawal' DIVXNH<DP DP RVR Journal of Advanced Concrete Technology, volume 13 (2015), pp. 479-488

\section{Click to Submit your Papers}




\title{
Investigation on the Pull-out Behavior of Deformed Bars in Cracked Reinforced Concrete
}

\author{
Koji Matsumoto $^{1 *}$, Tao $\mathrm{Wang}^{2}$, Daisuke Hayashi ${ }^{3}$, and Kohei Nagai ${ }^{4}$
}

\begin{abstract}
Pull-out tests and numerical analyses for deformed bar were performed on test specimens having cracks in concrete along the axial direction of the bar. The parameters for the experiment and analysis were: the maximum width of the initial crack, the presence or absence of a mechanical anchorage, the presence or absence of bond on either side of the deformed bar, and the presence or absence of a transverse bar. In both the experiments and the analyses, the pull-out load was applied at the end of the deformed bar after introducing the initial cracking by means of preloading. The results showed that the pull-out performance was greatly reduced by cracking along the axial direction of the bar. Also, it was seen that cracking along the deformed bar tended to occur only on one side of the bar. In the particular case of mechanical anchorage it was found that bending stresses occurred near the anchorage due to eccentric loading. The transverse bar increases the residual crack width when the same initial crack width was generated before unloading and also inducing spalling of the concrete cover due to cracking of the bond, resulting the reduction in pull-out strength.
\end{abstract}

\section{Introduction}

After the occurrence of major damage due to a large earthquake such as the Loma Prieta earthquake (1989: USA), the Great Hanshin Earthquake (1995: Japan), and the Jiji Earthquake (1999: Taiwan), etc., each time design standards are amended, and the seismic performance of the structures is enhanced. In recent years, in the case of RC structures, the quantity of shear reinforcement required has been increased significantly in order to achieve higher seismic performance. However, when the quantity of reinforcement is significantly increased the problem of reinforcement congestion is observed. If the quantity of reinforcement is excessive, it's assembly is not only expensive and time consuming, but also defects occur during placement of the concrete. This problem is particularly significant at beam-column joints where the arrangement of reinforcement from the column, the reinforcement from the beam, and the hook anchorage of the reinforcing steel is complex (Fig. 1).

One method to resolve reinforcement congestion is to use mechanical anchorages. With a mechanical anchorage, a projecting steel member is provided at the end of the reinforcement instead of a conventional hook an-

\footnotetext{
${ }^{1}$ Project Assistant Professor, Institute of Industrial Science, The University of Tokyo, Japan.

*Corresponding author, E-mail: km312@iis.u-tokyo.ac.jp

${ }^{2} \mathrm{Ph}$.D. Candidate, Graduate School of Engineering, The University of Tokyo, Japan.

${ }^{3}$ Researcher, Institute of Technology, Shimizu Corporation, Japan.

${ }^{4}$ Associate Professor, Institute of Industrial Science, The University of Tokyo, Japan.
}

chorage (Fig. 2), which enables the anchorage length to be reduced while maintaining the anchorage performance. It is considered that if hook anchorages can be eliminated in this way, reinforcement congestion can be greatly reduced. The testing and analysis of Takeyama et al. (Takeyama et al. 2008) is an example of previous research on the anchorage performance of reinforcement in concrete using mechanical anchorages. Takeyama et al. carried out static and fatigue pull-out tests using the embedded length to the mechanical anchorage as a parameter, and confirmed that mechanical anchorages have sufficient pull-out resistance compared to hook anchorages. Several types of mechanical anchorages have already been developed, and design recommendations have been published by the Japan Society of Civil Engineers (JSCE 2007).

However, at present the use of mechanical anchorages is limited to comparatively massive concrete only. This is because there is little knowledge regarding the performance of mechanical anchorages in concrete with small cover thickness. Oomori et al. (2009) investigated the anchorage performance of reinforcement using mechanical anchorages in cases with comparatively small cover thickness, and reported that bearing pressure from the mechanical anchorages caused cracking, fracture and spalling of side surface of the concrete cover, leading to ultimate failure, but the anchorage performance was not quantitatively evaluated. Murakami et al. (1997) conducted pull-out loading tests of mechanical anchorages focusing on the effect of concrete strength, cover depth and transverse reinforcement ratio. Also, Nakazawa et al. (2002) conducted pull-out loading tests of mechanical anchorages focusing on the failure mode such as cone failure and side cover spalling. However, the failure mechanism has not been sufficiently clarified yet because it is difficult to evaluate the stress state around the 
anchorage plates in experiments. Adachi et al. (2011) conducted finite element analysis (FEM) of Nakazawa $e t$ al.'s experiment and investigated the failure process. However, continuous element analyses such as FEM cannot reproduce the effect of localized cracks. Also, the JSCE recommendations (JSCE 2007) do not define the use of mechanical anchorages for the main reinforcement of beams or beam-column joints. This is may be due to the fact that when cracking occurs in the concrete near a bearing or joint due to impact loading or seismic loading (Fig. 3), the anchorage performance is unclear. Chun et al. (2007), Lee et al. (2009), Tadokoro et al. (2009) and Yoshitake et al. (2011) carried out loading tests on test specimens using mechanical anchorages in beam-column joints, and investigated their usefulness, but the relationship between the various types of cracking that occurred due to the loading and the anchorage performance

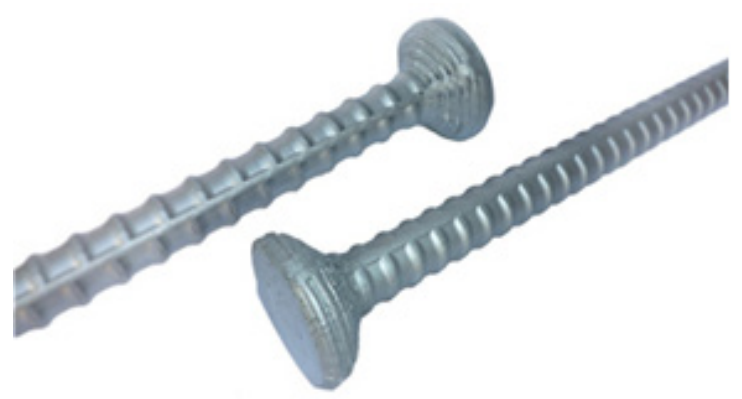

Fig. 2 Mechanical anchorage. of each reinforcement was not clarified.

The bond of deformed bars with concrete is mainly due to the transmission of force from the knots, but it is known that this transmitted force acts at an inclination to the bar axis (Goto 1971). So-called "bond splitting cracking" is cracking along the axis of the deformed bar that occurs by the component of the force transmitted from the knots in the direction normal to the axis of the bar pushing out the concrete cover. Conversely, if a crack is induced along the axis of the deformed bar in the concrete cover from the beginning, the resistance of the concrete cover to the component of force transmitted from the knots in the direction normal to the axis of the bar is reduced, hence it is expected that the bond force of the deformed bar will be reduced. Considering the splitting and cracking in the cover concrete in the research by Oomori et al., there is a high possibility that there is a similar mechanism in operation with mechanical anchorages, and that the anchorage performance is reduced by cracking along the axis of the deformed bar. Hence it is possible that that the cracking along the axis of the deformed bar particularly affects the bond performance of the deformed bars and the anchorage performance of mechanical anchorages. But at present there has been almost no research on this matter, and the situation is yet not clear. Delhomme et al. conducted pull-out tests of steel anchors with a plate anchorage embedded in concrete having initial cracks (Delhomme et al. 2015). They reported that the initial cracks affect the pull-out performance of the anchors, however, the failure mechanism
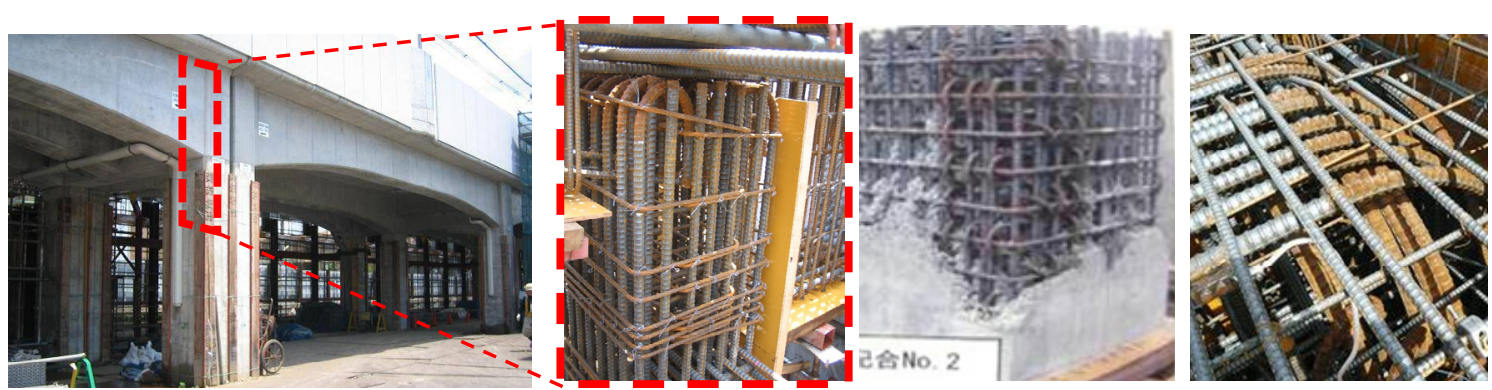

Fig. 1 Congestion of steel bars in beam-column joints.
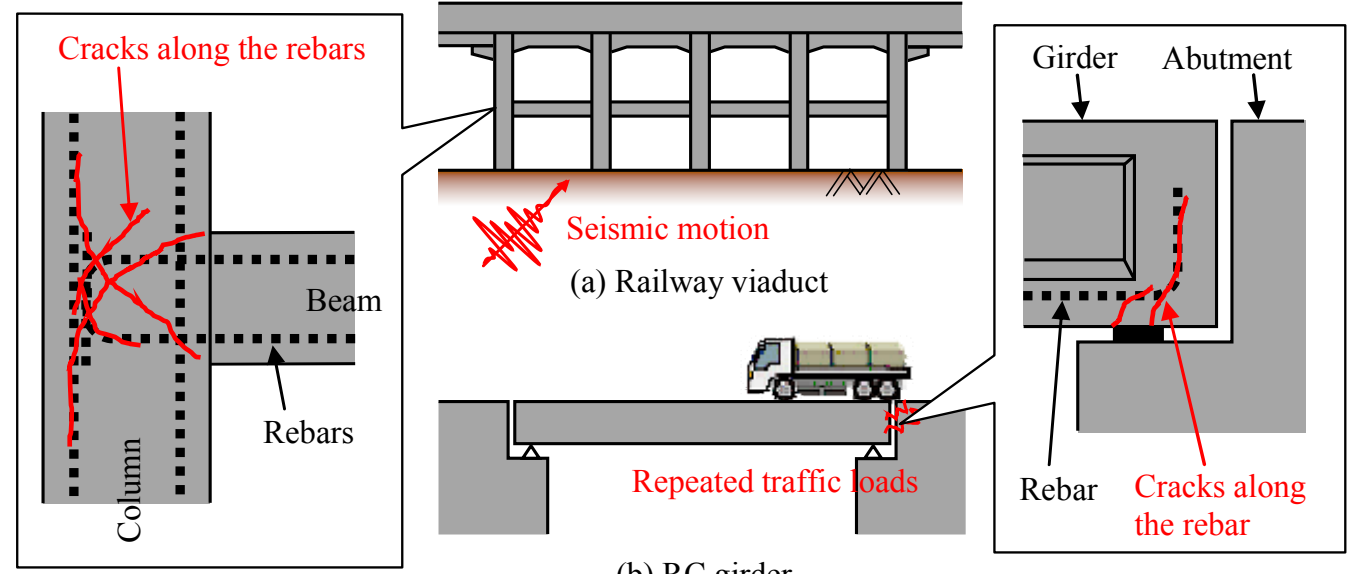

(b) RC girder

Fig. 3 Possibility of initial damages in concrete structures. 
Table 1 Specimens in the experiment and analysis.

\begin{tabular}{|c|c|c|c|c|c|}
\hline Specimen name & $\begin{array}{c}\text { Compressive strength of } \\
\text { concrete }\left(\mathrm{N} / \mathrm{mm}^{2}\right)\end{array}$ & $\begin{array}{c}\text { Presence of the } \\
\text { mechanical anchorage }\end{array}$ & $\begin{array}{l}\text { Removing friction } \\
\text { and adhesion }\end{array}$ & $\begin{array}{l}\text { Removing the } \\
\text { transverse bar }\end{array}$ & $\begin{array}{l}\text { Target maximum width of } \\
\text { the initial crack }(\mathrm{mm})\end{array}$ \\
\hline S-0.0-B-T(1) & \multirow{5}{*}{52.4} & No & No & No & - \\
\hline S-1.6-B-T & & No & No & No & 1.6 \\
\hline M-0.0-B-T(1) & & Yes & No & No & - \\
\hline M-1.0-B-T(1) & & Yes & No & No & 1.0 \\
\hline M-2.8-B-T & & Yes & No & No & 2.8 \\
\hline S-0.0-B-T(2) & \multirow{8}{*}{24.9} & No & No & No & - \\
\hline S-0.0-NB-T & & No & Yes & No & - \\
\hline S-0.0-B-NT & & No & No & Yes & - \\
\hline M-0.0-B-T(2) & & Yes & No & No & - \\
\hline M-0.0-NB-T & & Yes & Yes & No & - \\
\hline M-0.0-B-NT & & Yes & No & Yes & - \\
\hline M-1.0-B-T(2) & & Yes & No & No & 1.0 \\
\hline M-1.0-B-NT & & Yes & No & Yes & 1.0 \\
\hline
\end{tabular}

Table 2 Mix proportion of concrete.

\begin{tabular}{|c|c|c|c|c|c|c|c|c|}
\hline \multirow{2}{*}{$f_{c}{ }^{\prime}\left(\mathrm{N} / \mathrm{mm}^{2}\right)$} & \multirow{2}{*}{$W / C(\%)$} & \multirow{2}{*}{$G_{\max }(\mathrm{mm})$} & \multirow{2}{*}{$S / a(\%)$} & \multicolumn{5}{|c|}{ Unit quantity $\left(\mathrm{kg} / \mathrm{m}^{3}\right)$} \\
\cline { 5 - 9 } & & & $W$ & $C$ & $S$ & $G$ & $A E$ \\
\hline 52.4 & 51 & 20 & 44.9 & 177 & 350 & 775 & 969 & 0.874 \\
\hline 24.9 & 59 & 20 & 47.1 & 164 & 278 & 880 & 1007 & 3.058 \\
\hline
\end{tabular}

$f_{c}^{\prime}$ : compressive strength of concrete, $G_{\max }$ : maximum size of coarse aggregate, $S / a$ : fine aggregate ratio, $W:$ water, $C$ : cement,

$S$ : fine aggregate, $G$ : coarse aggregate, $A E$ : AE water reducing agent.

has not been clearly investigated yet because the internal stress condition cannot be observed in the experiment.

In this research pull-out load tests on test specimens with cracking induced by preloading (hereafter referred to as initial cracking) and numerical analyses were carried out in order to determine the effect of cracking along the axis of the deformed bar on the bond behavior of deformed bars and the anchorage performance of mechanical anchorages for cases with a comparatively small cover thickness. In the tests, the pull-out resistance of the deformed bars, the pull-out displacement, the strain distribution, and the cracking properties were investigated with the initial crack width, the presence or absence of bond on one side of the deformed bar, and the presence or absence of a transverse bar as parameters. In the numerical analysis, the effect of the various factors such as cracking patterns in the concrete, properties of the deformed bar deformation, etc., on the pull-out failure mechanisms was investigated. In this study, a 3-dimensional meso-scale discrete analysis method, which enables to simulate the mechanical behavior in local regions around cracks and bearing forces from steel elements in a 3-dimensional space, was used.

\section{Outline of the experiment}

\subsection{Specimens}

Figure 4 and Table 1 show an outline of the test specimens and a list of the test cases respectively. There were a total of 13 test specimens, and the experimental pa- rameters were: the presence or absence of a mechanical anchorage, the target maximum width of the initial crack, the presence or absence of bond on one side of the deformed bar, and the presence or absence of a transverse bar. The deformed bar used in the pull-out loading tests was a thread knot deformed bar with a nominal diameter of $25.4 \mathrm{~mm}$ (D25). The anchorage lengths in cases where a mechanical anchorage was not used and in cases where a mechanical anchorage was used were $450 \mathrm{~mm}$ and 200 $\mathrm{mm}$ respectively. The anchorage length $(450 \mathrm{~mm})$ in the cases where the mechanical anchorage was not used was determined using the equation by Orangun et al. (1977). Also, the anchorage length $(200 \mathrm{~mm})$ in the cases where the mechanical anchorage was used was calculated by deducting $10 \mathrm{D}(10 \times 25=250 \mathrm{~mm})$ from the value calculated by the equation by Orangun et al., in accordance with the JSCE recommendations (JSCE 2007). However, in order to prevent localized failure in each test specimen, an unbonded region was provided $150 \mathrm{~mm}$ from the loaded end. As shown in Figs. 4(a) and (b), transverse bars were placed at a $100 \mathrm{~mm}$ pitch within the cover concrete, immediately above the deformed bar that was subjected to pull-out. However, as described later, for the cases where the transverse bar was excluded, the transverse bar was excluded at the position closest to the mechanical anchorage. Note that in order to investigate the influence of concrete strength, two specimens were prepared for S-0.0-B-T, M-0.0-B-T, and M-2.8-B-T. Table 2 shows the concrete mix proportions, and Table 3 shows the material properties of the deformed bar and 
transverse bar. For the test specimens with $f_{c}{ }^{\prime}$ of 52.4 $\mathrm{N} / \mathrm{mm}^{2}$, pull-out rebar (1) and transverse bar (1) were used, and for test specimens with $f_{c}^{\prime}$ of $24.9 \mathrm{~N} / \mathrm{mm}^{2}$, pull-out rebar (2) and transverse bar (2) were used.

The following is a description of the operating procedures for each of the test parameters.

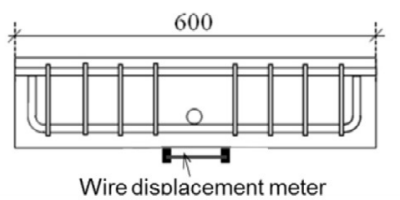

Unit: mm
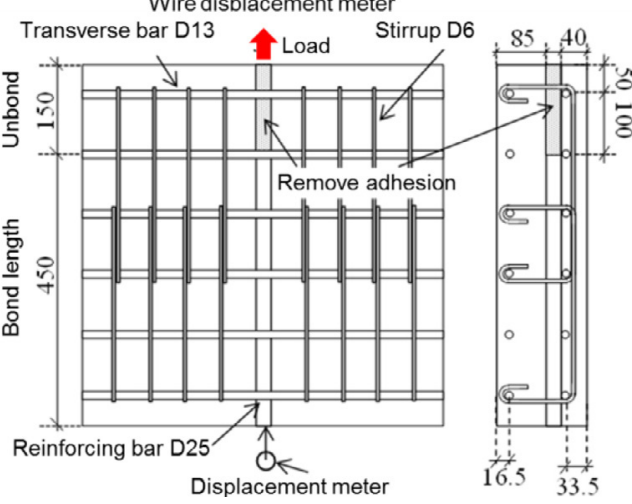

(a) Specimens without mechanical anchorage

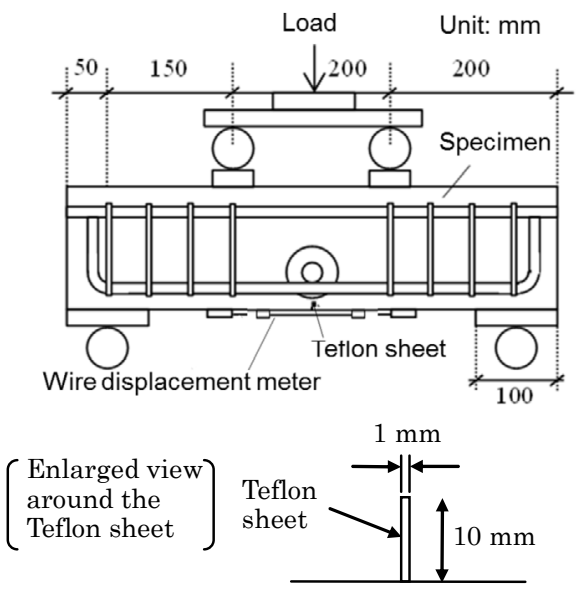

(c) Prior loading to induce initial crack

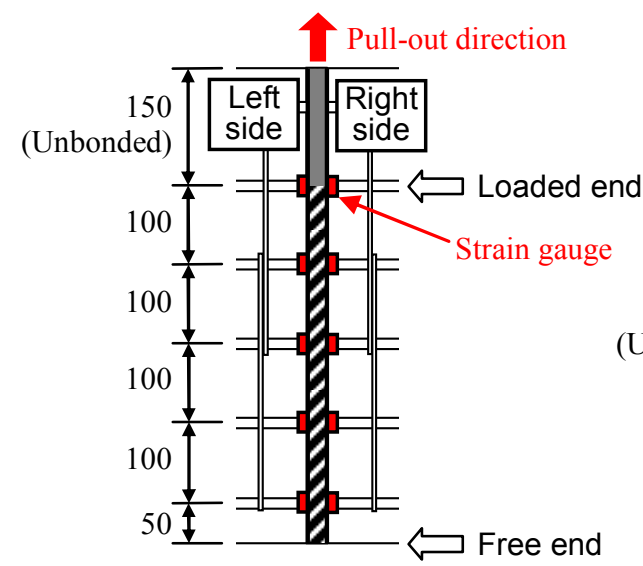

i) Specimens without mechanical anchorage
Table 3 Material properties of steel bars.

\begin{tabular}{|c|c|c|c|c|}
\hline Name & $\begin{array}{c}\text { Designation } \\
\text { by JIS }\end{array}$ & $\begin{array}{c}D \\
(\mathrm{~mm})\end{array}$ & $\begin{array}{c}f_{y} \\
\left(\mathrm{~N} / \mathrm{mm}^{2}\right)\end{array}$ & $\begin{array}{c}E_{s} \\
\left(\mathrm{~N} / \mathrm{mm}^{2}\right)\end{array}$ \\
\hline Pull-out rebar (1) & D25 & 25.4 & 547 & 190 \\
\hline Pull-out rebar (2) & D25 & 25.4 & 534 & 190 \\
\hline Transverse bar (1) & D13 & 12.7 & 397 & 190 \\
\hline Transverse bar (2) & D13 & 12.7 & 391 & 190 \\
\hline
\end{tabular}

$D$ : nominal diameter, $f_{y}$ : yield strength, $E_{s}$ : Young's modulus.

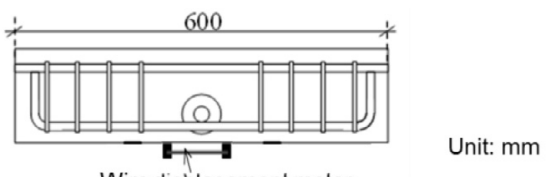

Wire displacement meter

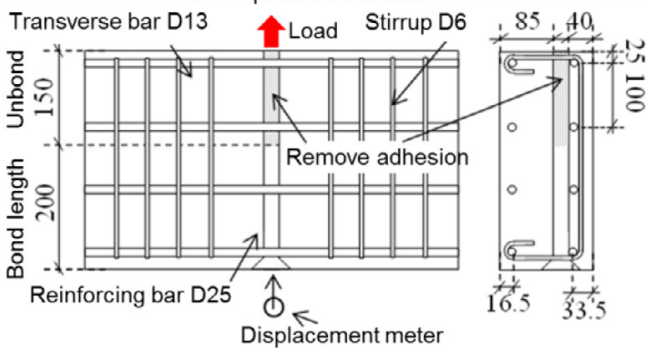

(b) Specimens with mechanical anchorage

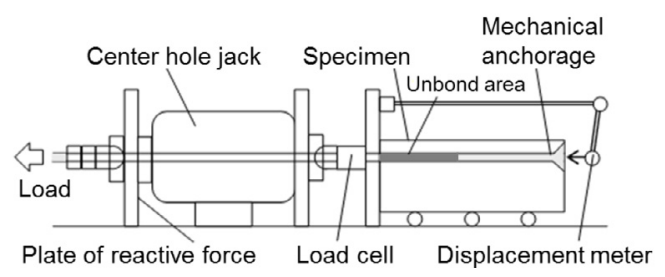

(d) Pull-out loading

Fig. 4 Outline of the experimental specimens. 


\subsubsection{Method of inducing the initial crack}

Preloading was carried out on the test specimens so as to induce the initial crack prior to applying the pull-out load on the deformed bar. This initial crack represents a crack along the rebar induced by external loadings such as earthquakes and impact loadings as shown in Fig. 3. Since the cracking mechanism is different from that induced by only a pull-out loading, the initial crack is expected to affect the pull-out behavior of the deformed bars. Figure 4(c) shows an overview of the preloading. As shown in Fig. 4(c), a bending load was applied with an arrangement having the deformed bar that was to be pulled out, at the center of the span, and by embedding a $1 \mathrm{~mm}$ thick $10 \mathrm{~mm}$ height Teflon sheet in the concrete cover directly below the deformed bar, for inducing the bending crack. In order to control the crack width, wire displacement gauges were installed on the bottom surface of the test specimens at positions $175 \mathrm{~mm}$ and 50 $\mathrm{mm}$ respectively from the free end or the mechanical anchorage, and when the set maximum initial crack for each specimen was reached the bending load was stopped and unloading was carried out. In this study, crack widths were controlled to induce initial damages considering that, in general, crack appearances at the outer surface are evaluated in visual inspection of structures. That is, this study compares the effect of mechanical anchorage under the same deterioration grade of existing structures.

\subsubsection{Unbonding one side of the deformed bar}

As described later in Section 3, cracks induced by preloading through bending tends to propagate around one side of the deformed bar, and when the pull-out load is acting, an eccentric load effect is applied. Therefore the effect of the initial crack propagation pattern was investigated by eliminating the bond on one side of the deformed bar. In this study, the total bond of deformed bars is assumed to consist of bearing forces from knots, friction, and adhesion. As shown in Fig. 5, by applying a polyethylene wrap which retained the knot shape of the deformed bar, the friction and adhesion between the steel and the concrete was eliminated. Note that in this paper, as shown in Fig. 5, when the concrete cover side is on the bottom surface, and in a top surface view in which the point of application of the pull-out load is downward, the

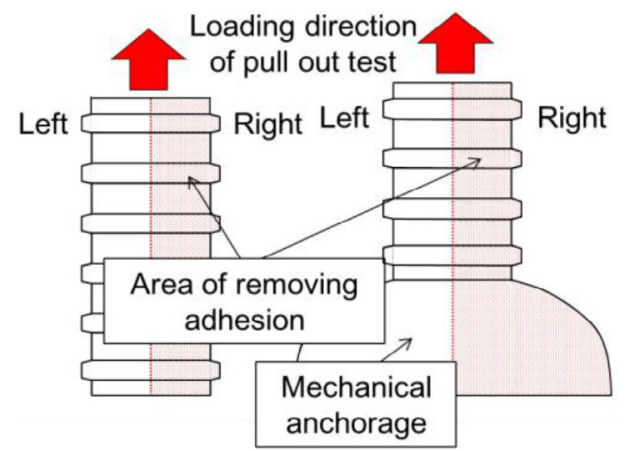

Fig. 5 Method for removing bond at the one side of steel bars. right side of the deformed bar is referred to as the "right side" and the left side is referred to as the "left side". Unbonding using the polyethylene wrap was carried out on the right side only.

\subsubsection{Presence of transverse bars}

As reported by Oomori et al. (2009), it is known that mechanical anchorages generate bearing stress in the off-axis direction of the reinforcement, and in particular case of small thickness of concrete cover the constraint forces are small, so cracking by splitting can easily occur. Providing reinforcement in the transverse direction with respect to the reinforcement within the cover concrete can potentially reduce cracking by splitting and concrete spalling, and affect the pull-out properties. Therefore in this research, test specimens were prepared in which a transverse bar was eliminated, focusing particularly on the effect of the transverse reinforcement near the mechanical anchorage.

\subsubsection{Measurement instruments}

The measurement items in these tests were the bending load (during preloading), the initial crack width (during preloading and during pull-out loading), the pull-out load (during pull-out loading), the pull-out bar strain (during pull-out loading), and slip at the free end or the anchorage end (during pull-out loading). As shown in Fig. 4(e), strain gauges with a $2 \mathrm{~mm}$ measurement length were applied to both sides of the pull-out bar, to measure the strain. A contact type displacement meter was used to measure the slip at the free end or the anchorage end. As shown in Fig. 4(d), by installing the base of a displacement meter on a bearing plate, the relative displacement between the loading point side concrete and the free end or the anchorage end was measured.

\section{Results of the experiment}

\subsection{Induction of the initial cracks by preloading}

Table 1 shows the values of the maximum initial crack widths actually induced by preloading and the initial crack widths when unloaded. The induced maximum crack widths were all maintained within a maximum $11 \%$ error band from the target values $(1.0 \mathrm{~mm}, 1.6 \mathrm{~mm}$ and $2.8 \mathrm{~mm}$ ). Since over $3 \mathrm{~mm}$ crack width was observed in the previous study (Yoshitake et al. 2011) on the loading tests of beam-column joints in the post peak, the target maximum crack widths were set so that they represent damages induced by comparatively severe earthquakes. Figure 6 shows the load-initial crack width relationship during preloading. As shown in this figure, even though the maximum initial crack widths before unloading were the same, the slope of the unloading curve differed depending on the presence or absence of the transverse bar, and the residual crack width tended to be larger in the cases with the transverse bar. The effect on the pull-out behaviors of the deformed bar is described later in Section 3.2.4. 
Table 4 Result of the experiment and analysis.

\begin{tabular}{|c|c|c|c|c|c|c|c|c|}
\hline \multirow{3}{*}{ Specimen name } & \multicolumn{4}{|c|}{ Width of the initial crack (mm) } & \multicolumn{2}{|c|}{ Max pull-out load (kN) } & \multicolumn{2}{|c|}{ Failure mode } \\
\hline & \multicolumn{2}{|c|}{ Exp. } & \multicolumn{2}{|c|}{ Ana. } & \multirow{2}{*}{ Exp. } & \multirow{2}{*}{ Ana. } & \multirow{2}{*}{ Exp. } & \multirow{2}{*}{ Ana. } \\
\hline & Max & Unload & Max & Unload & & & & \\
\hline S-0.0-B-T(1) & - & - & - & - & 258.9 & 286.5 & Yielding & Splitting \\
\hline S-1.6-B-T & 1.75 & 1.18 & 1.58 & 1.27 & 185.5 & 188.0 & Splitting & Splitting \\
\hline M-0.0-B-T(1) & - & - & - & - & 270.1 & 274.6 & Cone & Cone \\
\hline M-1.0-B-T(1) & 1.04 & 0.63 & 0.97 & 0.72 & 247.4 & 247.1 & Cone & Cone \\
\hline M-2.8-B-T & 2.76 & 2.34 & 2.75 & 2.44 & 182.7 & 183.6 & Cone & Cone \\
\hline S-0.0-B-T(2) & - & - & - & - & 205.4 & 204.9 & Splitting & Splitting \\
\hline S-0.0-NB-T & - & - & - & - & 136.3 & 135.6 & Splitting & Splitting \\
\hline S-0.0-B-NT & - & - & - & - & 217.9 & 220.3 & Splitting & Splitting \\
\hline M-0.0-B-T(2) & - & - & - & - & 184.6 & 181.8 & Cone & Cone \\
\hline M-0.0-NB-T & - & - & - & - & 139.2 & 143.6 & Cone & Cone \\
\hline M-0.0-B-NT & - & - & - & - & 194.7 & 195.3 & Cone & Cone \\
\hline M-1.0-B-T(2) & 1.11 & 0.81 & 1.07 & 0.91 & 145.2 & 139.9 & Cone & Cone \\
\hline M-1.0-B-NT & 1.06 & 0.61 & 0.93 & 0.69 & 184.5 & 183.3 & Cone & Cone \\
\hline
\end{tabular}

\subsection{Pull-out test results}

Table 4 shows the pull-out load capacity and failure mode for each test specimen. Also, Fig. 7 shows the relationship between the pull-out load and the pull-out displacement of the free end or the anchorage end. The following is an explanation of the effect of each test parameter.

\subsection{Effect of the mechanical anchorage}

The pull-out load capacity of S-0.0-B-T(1) and S-0.0-B-T(2) in which a mechanical anchorage was not used was $259 \mathrm{kN}$ and $205 \mathrm{kN}$ respectively, and in contrast the pull-out load capacity of M-0.0-B-T(1) and M-0.0-B-T(2) in which a mechanical anchorage was provided was $254 \mathrm{kN}$ and $185 \mathrm{kN}$ respectively. The pull-out load capacity was slightly reduced even though the anchorage length in the cases that used a mechanical anchorage was based on the JSCE guidelines. This is considered to be because the concrete cover was comparatively small in the tests. Figure 8(b) shows the failure state of M-0.0-B-T(1). Inclined cracking occurred in the concrete cover at the position of the mechanical an- chorage, and the bearing force from the mechanical anchorage in the off-axis direction of the reinforcement pushed the cover concrete out in a cone shape, thereby causing pull-out failure.

\subsubsection{Effect of initial crack width}

Figure 9 shows the relationship between the maximum initial crack width and the pull-out load capacity. For both the cases that did not use a mechanical anchorage and the cases that did use a mechanical anchorage, as the maximum initial crack width increased, the pull-out load capacity was reduced. However, the slope of the approximated straight lines in the figure is smaller in the cases using a mechanical anchorage, so it is considered that the effect of the initial crack can be reduced by using a mechanical anchorage.

Figures 8(a) and (c) show the failure states for S-1.6-B-T and M-1.0-B-T(1). In S-1.6-B-T which had no mechanical anchorage, pull-out failure occurred by splitting failure by enlargement of the initial crack width along the deformed bar. On the other hand in M-1.0-B-T(1) which had a mechanical anchorage, cone

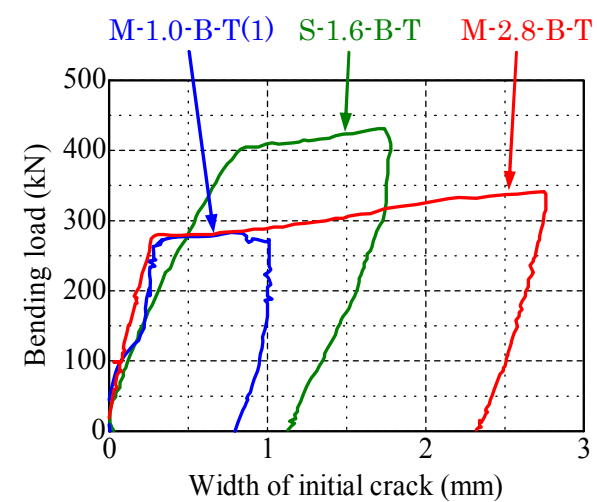

(a) Different target of maximum crack widths

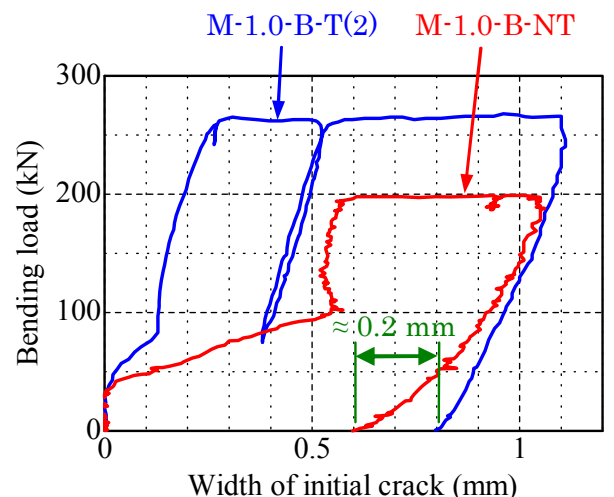

(b) Effect of transverse bar

Fig. 6 Load-initial crack width relationships in the prior loading. 


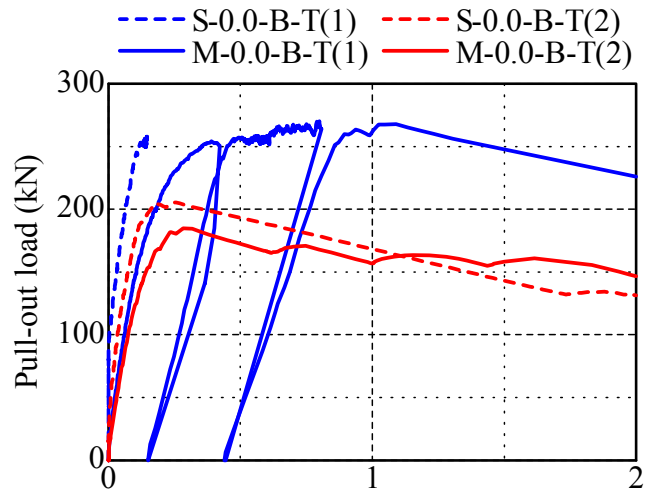

Slip at the free end or anchorage $(\mathrm{mm})$

(a) Effect of mechanical anchorage

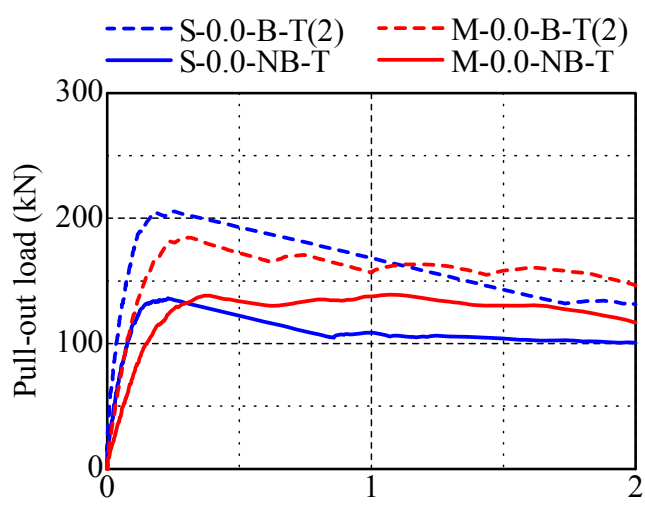

Slip at the free end or anchorage (mm)

(c) Effect of bond at the one side of rebar

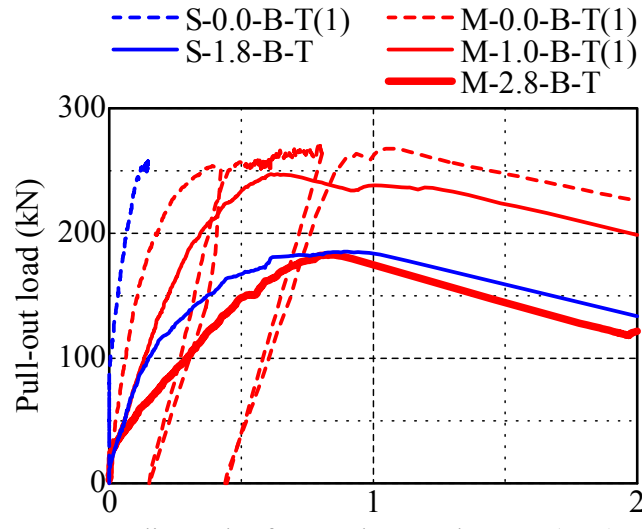

Slip at the free end or anchorage (mm)

(b) Effect of width of initial crack

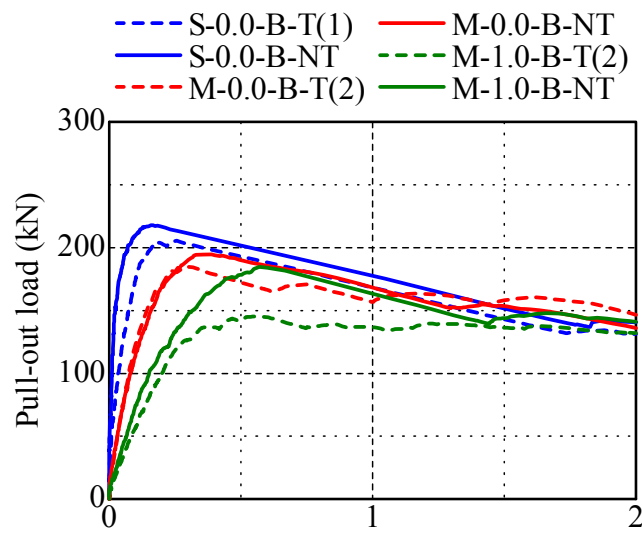

Slip at the free end or anchorage $(\mathrm{mm})$

(d) Effect of transverse bars

Fig. 7 Pull-out load-slip at the free end or anchorage relationships.

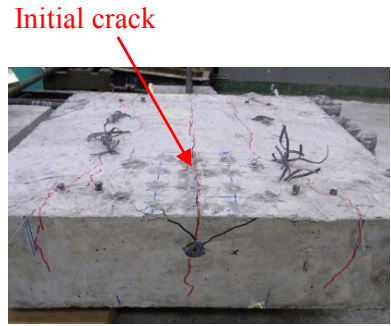

(a) S-1.6-B-T

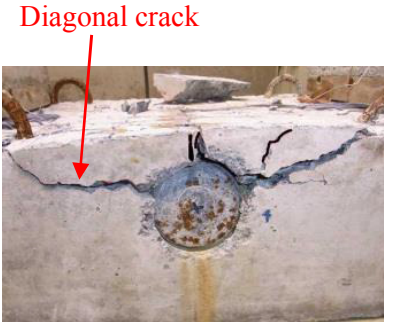

(b) M-0.0-B-T(1)

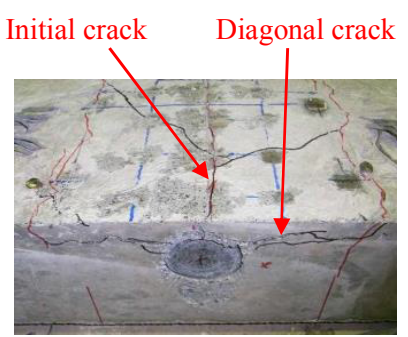

(c) M-1.0-B-T(1)

Fig. 8 Pull-out failure pattern of deformed bars with/without mechanical anchorages in thin cover concrete.

failure occurred together with enlargement of the initial crack width. However, by comparison with M-0.0-B-T(1) which had no initial crack, the angle of the inclined crack that caused the cone failure was smaller.

Figure 10 shows the relationship between the pull-out load and the right side and left side strain in the cases that did not use a mechanical anchorage. In S-0.0-B-T(1) in which an initial crack was not induced, there was almost no difference between the right side and left side strains regardless of the distance from the loaded end. In contrast in S-1.6-B-T in which the initial strain was induced, a slight difference was found between the right side and left side strains. This is inferred because as shown in Fig. 11, the initial crack is formed so that it goes around the reinforcement to the left or the right, so the bond between

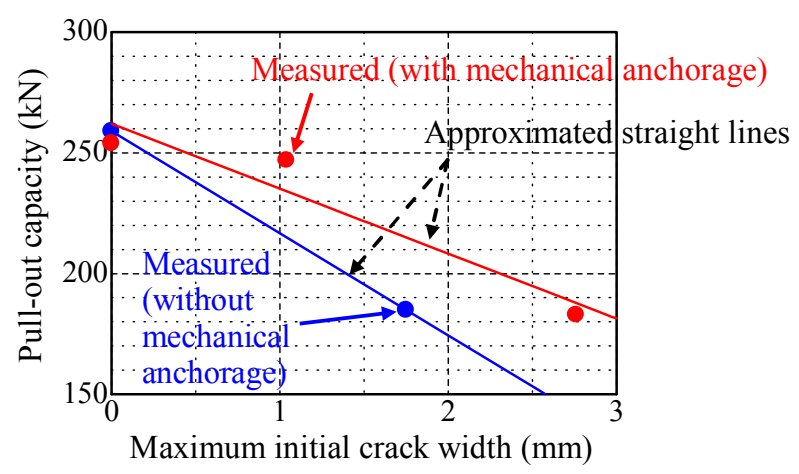

Fig. 9 Effect of the maximum initial crack width on pull-out capacity. 
the reinforcement and the concrete differs between the left and right. It is inferred that when there is an initial crack along the reinforcement, the reinforcement subjected to the pull-out load is not in a pure uniaxial stress state, and deformation is produced in the off-axis direction.

Figure 12 shows the relationship between the pull-out load and the right side and left side strain in the cases that did use a mechanical anchorage. It can be seen that there is a large difference between the right side strain and the left side strain particularly at the position near the mechanical anchorage. Also, it can be seen that in the cases where the initial crack was induced, the relationship of magnitude between the right side and left side strains tends to be reversed in accordance with distance from the anchorage.

This is considered because the mechanical anchorage resists not only the pull-out load in the axial direction of the reinforcement, but also a bending moment, and the boundary condition resembles that of a fixed end, so a large bending moment is produced.

\subsubsection{Effect of the presence or absence of bond on one side of the reinforcement}

To verify the production of deformation in the off-axis direction due to the elimination of bond on one side of the reinforcement as described in Section 3.2.2, and to investigate the relationship between the bond elimination position and the off-axis direction deformation, test specimens were produced that were unbonded on one side. Comparing S-0.0-B-T(2), S-0.0-NB-T, M-0.0-B-T(2), and M-0.0-NB-T as shown in Table 4, it can be seen that regardless of the presence or absence of a mechanical anchorage, the pull-out resistance has been greatly reduced by unbonding. Figure 13 shows the changes in right side and left side strains. For S-0.0-NB-T which did not use a mechanical anchorage a significant difference between the right side and left side strains was not produced, but for M-0.0-NB-T which did use a mechanical anchorage, the right side and left side strains were different, so deformation in the off-axis direction was found. Focusing on the unbonding position, unbonding was carried out only on the right side, and at $x$ $=50 \mathrm{~mm}$ and $100 \mathrm{~mm}$ which were comparatively close to the loading point, it can be seen that the right side strain is greater than the left side strain. On the other hand, at the positions $x=150 \mathrm{~mm}$ and $200 \mathrm{~mm}$ which were close to the mechanical anchorage, this trend was reversed, and the left side strain was greater than the right side strain. This is considered because of the effect of the mechanical anchorage behaving as a fixed end. This deformation behavior is explained in detail in Chapter 5 using the results of numerical analysis.

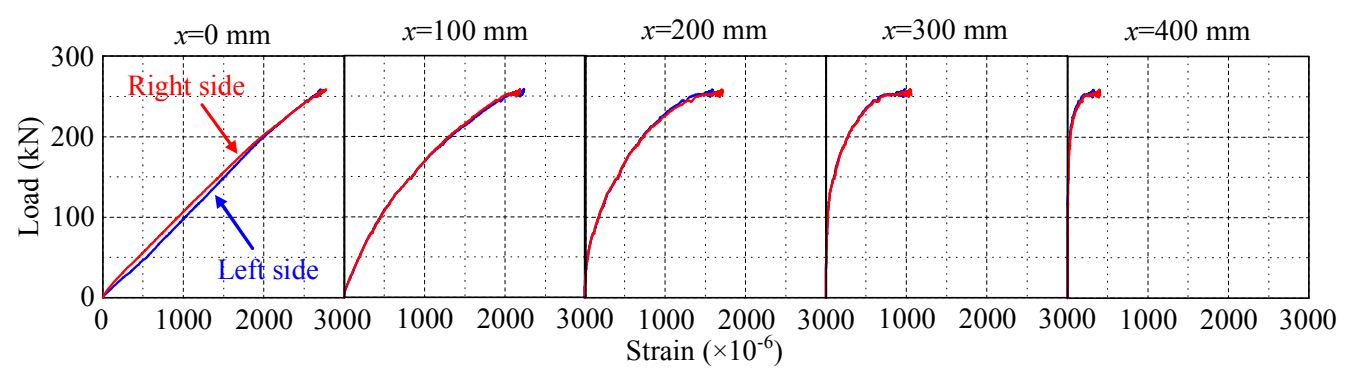

(a) $\mathrm{S}-0.0-\mathrm{B}-\mathrm{T}(1)$

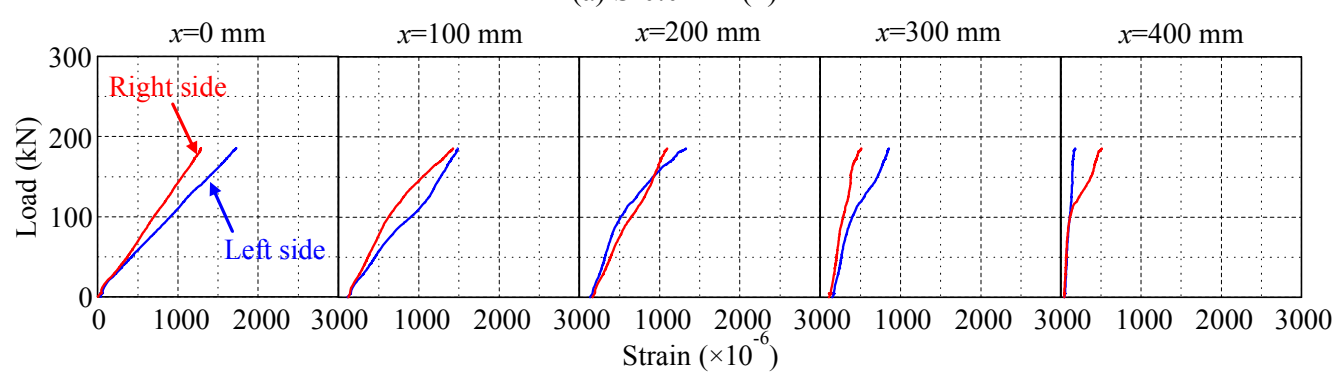

(b) S-1.6-B-T(1)

Fig. 10 Load-strain of pull-out bar relationships in the cases without mechanical anchorage $(x=$ distance from the loaded end).

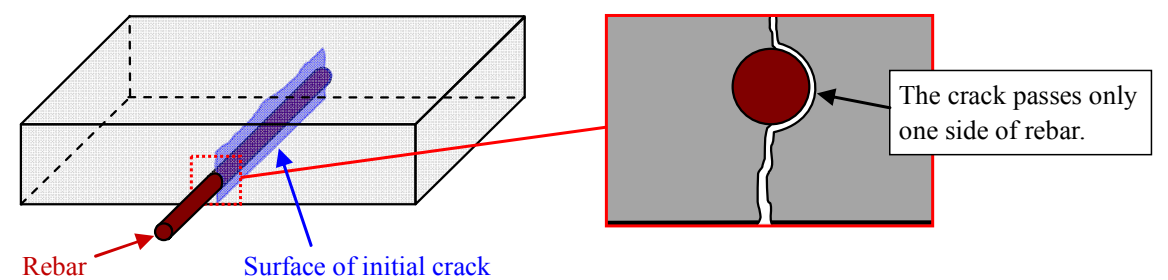

Fig. 11 Pattern of initial cracks around the steel bars. 


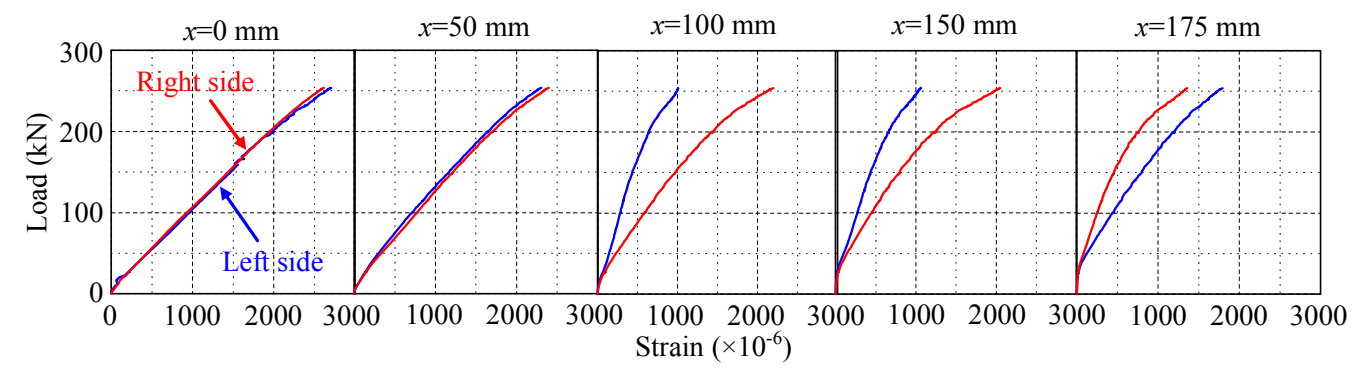

(a) M-0.0-B-T(1)

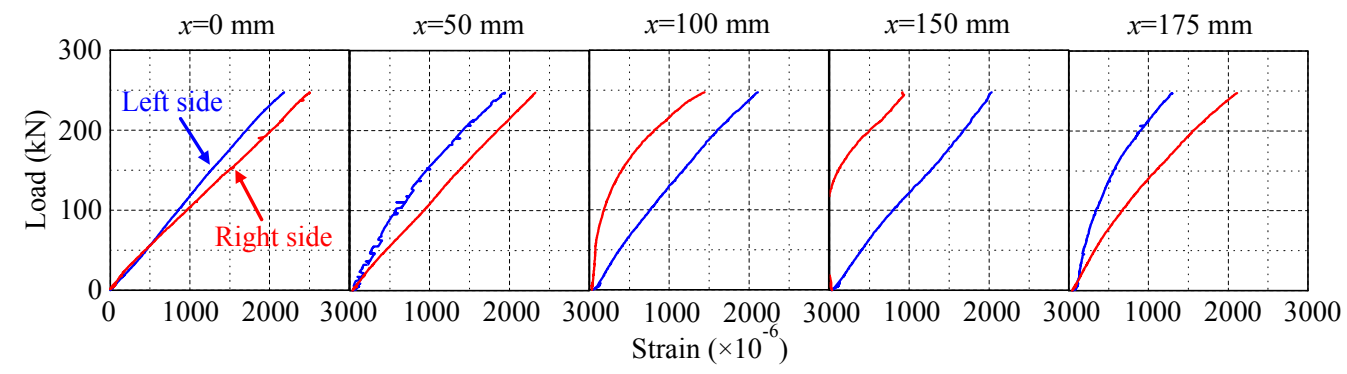

(b) M-1.0-B-T(1)

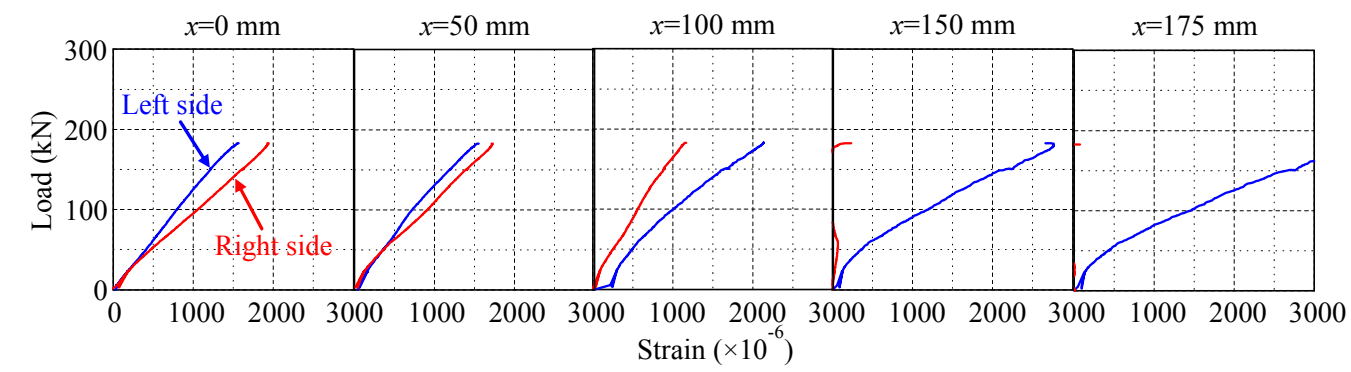

(c) M-2.8-B-T

Fig. 12 Load-strain of pull-out bar relationships in the cases with mechanical anchorage $(x=$ distance from the loaded

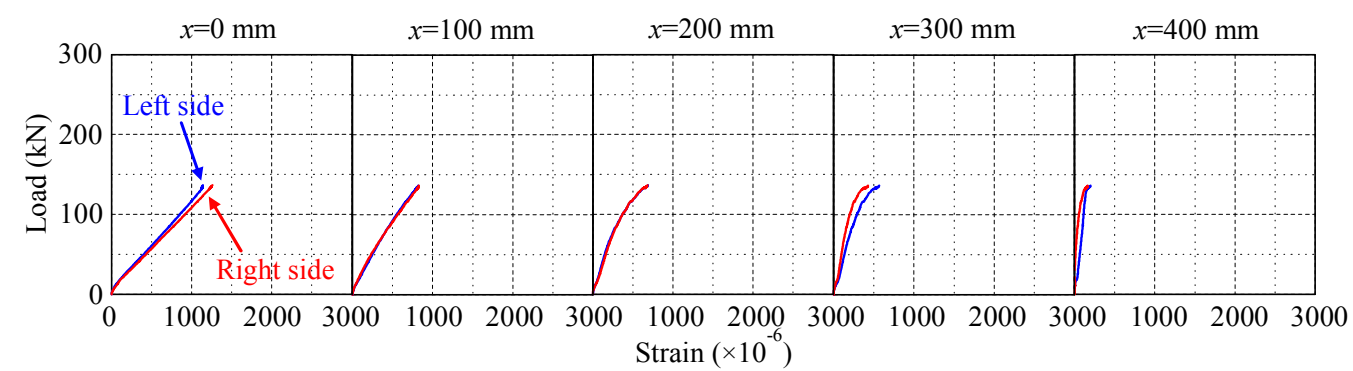

(a) S-0.0-NB-T

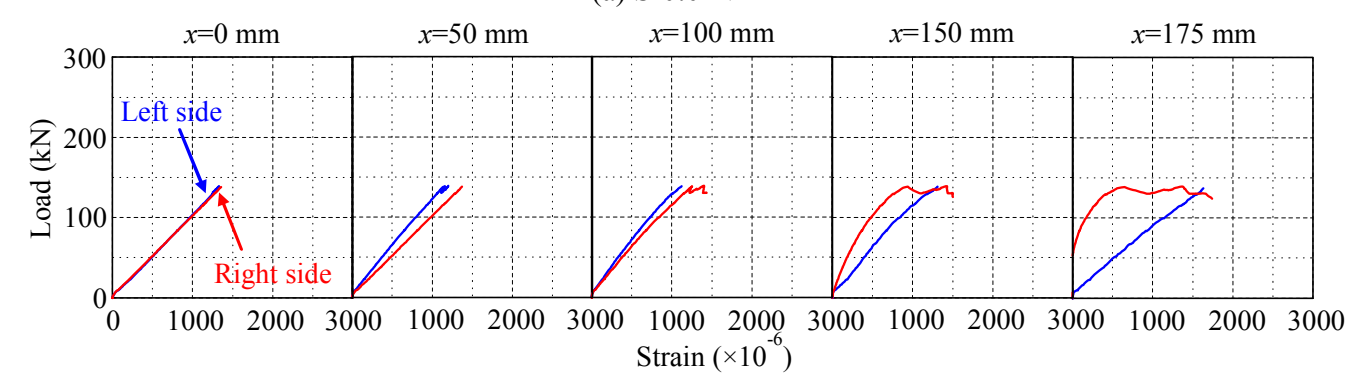

(b) M-0.0-NB-T

Fig. 13 Effect of bond at the one side of steel bar on the strain development ( $x=$ distance from the loaded end). 


\subsubsection{Effect of the presence or absence of transverse reinforcement}

Figure 7(d) shows the pull-out load - slip relationship at the free end or the anchorage end for the cases where the transverse bar was removed near the mechanical anchorage (S-0.0-B-NT, M-0.0-B-NT and M-1.0-B-NT) and the cases where the transverse bar was provided (S-0.0-B-T(2), M-0.0-B-T(2) and M-1.0-B-T(2)). It can be seen that when an initial crack was not induced, the effect of the transverse bar on the pull-out load resistance was small, regardless of the presence or absence of the mechanical anchorage. On the other hand, in the cases where the initial crack was induced, clear differences were found, with the pull-out load being greater when the transverse bar was omitted. This is considered to be because in the cases where the transverse bar was removed, the residual initial crack width was smaller, as shown in Fig. 6. When the maximum values of the initial crack widths experienced previously are compared under the same conditions, as in this research, if the transverse reinforcement is yielded and residual strain occurs in the transverse reinforcement, crack closure is obstructed by the transverse reinforcement during unloading, so the residual initial crack width is increased, and this is considered to decrease the constraint of the concrete cover on the deformed bar or the mechanical anchorage.

\section{Outline of the numerical analysis}

\subsection{Objective}

In the tests described up till the previous section, the pull-out behavior was investigated while using mechanical anchorages with small concrete cover with an initial crack width and presence and absence of transverse reinforcement. However, in the tests the stress distribution within the test specimens, the state of the cracking, and the state of deformation of the reinforcement was not clear, so it was not possible to investigate the failure mechanisms in detail. Therefore in this research a 3-dimensional numerical analysis was also carried out, to confirm the validity of the analysis model and to investigate the failure mechanisms. Numerical analysis was carried out for all the test cases shown in Table 1.

\subsection{Method of the analysis}

In this research a meso-scale analysis was carried out using the Rigid Body-Spring Model (hereafter, RBSM). RBSM is one method of discrete analysis developed by Kawai, in which the object under consideration is modeled by dividing it into multiple rigid elements, and connecting the rigid elements with springs (Kawai et al. 1978). Crack extension and enlargement of the crack width are represented by separation of adjacent elements. In the case of a 3-dimensional model, one normal direction spring and two shear direction springs are provided between adjacent rigid elements, as shown in Fig. 14(a).

As shown in Fig. 14(b), in the meso-scale analysis carried out in this research, the cross-section of the deformed bar was divided into many elements, and the shape of the knots was also modeled. In the normal finite element method, the bond of reinforcement is represented by spring elements, etc., arranged in the direction of axis of reinforcement between the reinforcement and the concrete elements, and the bond-slip relationship of the spring element does not take into consideration those stresses which are in the off-axis direction of the reinforcement. Therefore, the relationship between the bond behavior of the deformed bar and the stresses in the off-axis direction of the bar, as pointed out by Goto (1971), cannot be taken into consideration. As a result it is not possible to investigate the effect of spalling of concrete due to bond failure, and the constraint effect of the concrete cover on the bond behavior. By modeling the shape of the knots, as in this research, it is possible to obtain the magnitude and direction of the forces from the knots through the results of the analysis, as pointed out by Goto. The shape of the knots affects the cracking behavior around the deformed bars. In the previous study (Hayashi et al. 2013) in which shape of the knots is modeled same as that in this study, crack development around the deformed bars was verified by conducting pull-out analysis of cylindrical specimens. It was confirmed that the model of deformed bars can reproduce conical shape of cracking pattern as observed by Goto (1971). The authors also have confirmed that it is possible to reproduce the effect of transverse reinforcement on the spalling of cover concrete due to bond failure of deformed bars using this analysis method (Hayashi et al.

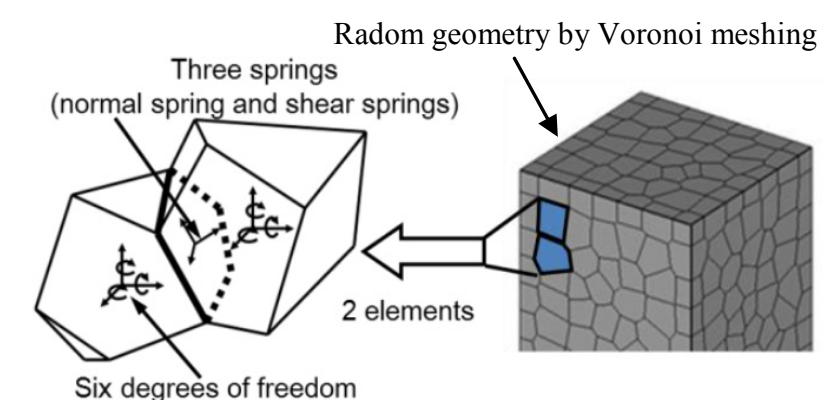

(a) Random geometry and springs interconnected between adjacent elements

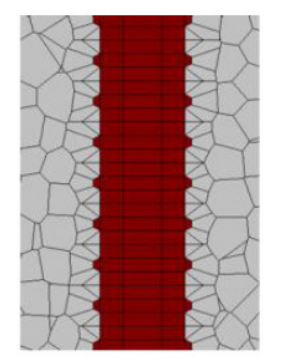

Meshing around rebar

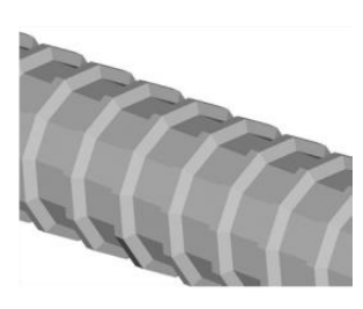

$\underline{\text { Regular shape }}$

(b) Modeling of deformed bars

Fig. 14 Concept of RBSM (3D). 
2013).

A random shape using Voronoi diagram was adopted for the concrete element meshing, so that the crack directions were not dependent on the element meshing. The dimensions of the concrete elements were $10 \mathrm{~mm}^{3}$ to $20 \mathrm{~mm}^{3}$, taking into consideration the maximum size of the coarse aggregate. Figure $\mathbf{1 5}$ shows the analysis model. The loading plate and the bearing plate during preloading were modeled as rigid elements regardless of the presence or absence of a mechanical anchorage, and by applying a forced displacement in the vertical direction to the loading plate, the initial crack was induced in the center of the span. The loading plate and the bearing plate were pin hinged, and the bearing plate was free in the horizontal direction. During pull-out loading, a forced displacement was applied to the element at the end of the deformed bar that was being pulled out. By fixing the concrete elements in the pull-out direction on the front side in the figure, the reaction was provided. It
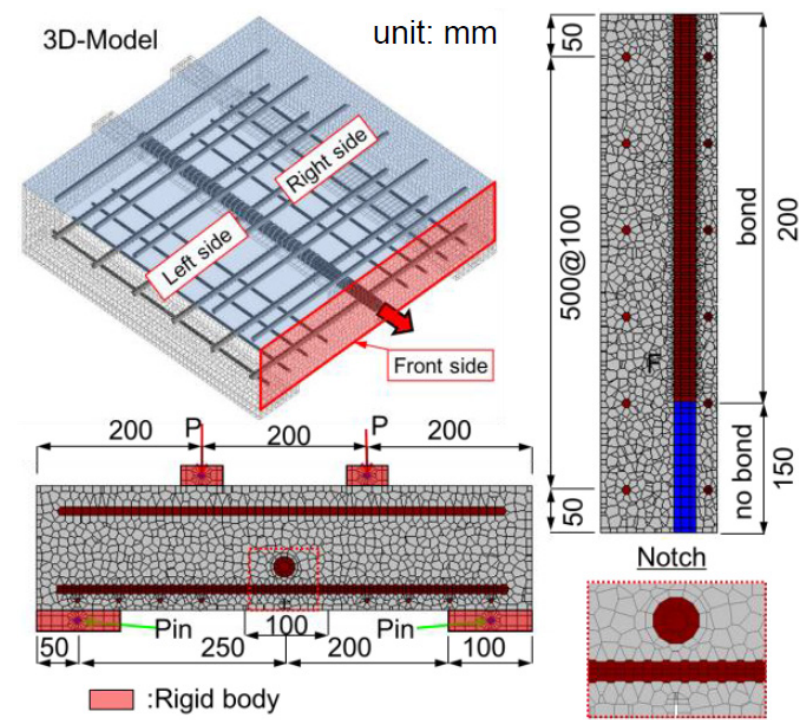

(a) Specimens without mechanical anchorage

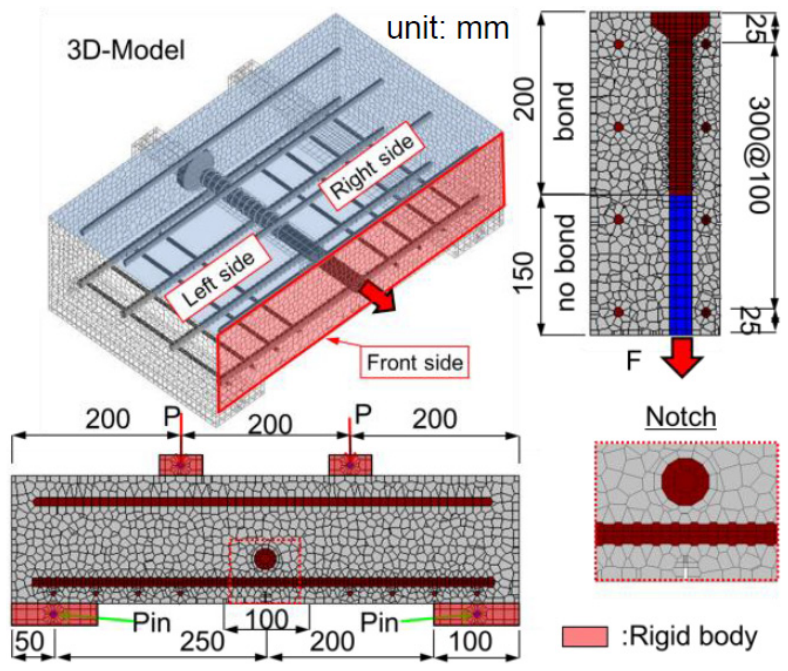

(b) Specimens with mechanical anchorage

Fig. 15 Analytical models. is to be noted that the definitions of right side and left side are the same as for the experiments.

\subsection{Constitutive models \\ 4.3.1 Concrete}

Figure 16 shows the concrete stress-strain model. For the spring in the normal direction, elastic behavior was taken into consideration on the compression side, and tension softening on the tension side. At the meso-scale, the characteristic of this analysis model is that the concrete does not fail under compressive stresses, based on the concept that the failure of concrete observed at the macro-scale occurs due to the accumulation of tensile failure and shear failure (Nagai et al. 2004). From the model used in the previous study (Hayashi et al. 2013), the tension softening branch shown in Figs. 16(a) and 18 was changed to bilinear model to reproduce the fracture energy of concrete under bending.

For the shear direction springs, it is assumed that the behavior is elastic until the failure criterion is reached and after the failure criterion is reached $\tau=\tau_{\max }$, as shown in Fig. 16(c). However, in order to represent the reduction in interlocking effect due to crack opening, $\tau$ is reduced in association with deformation of the normal direction spring, as shown in Fig. 16(d).

\subsubsection{Steel}

Figure 17 and Eqs. (1), (2) and (3) show the stress-strain model of the reinforcement. The model of Shima et al. (1987) was adopted for the stress-strain relationship of the normal direction spring in the hardening region. However, the initial strain of strain hardening was $1.5 \%$. Also, the stress-strain relationship during unloading and reloading followed the initial slope. On the other hand, the shear direction spring always exhibited elastic behavior.

$$
\begin{aligned}
& \sigma=E_{s} \varepsilon \quad \varepsilon<\varepsilon_{y} \\
& \sigma=f_{y} \quad \varepsilon_{y}<\varepsilon<\varepsilon_{s h} \\
& \sigma=f_{y}+\left(1-e^{\varepsilon_{s h}-\varepsilon / k}\right)\left(1.01 f_{u}-f_{y}\right) \quad \varepsilon>\varepsilon_{s h}
\end{aligned}
$$

where,

$$
k=0.032\left(400 / f_{y}\right)^{1 / 3}
$$

$\sigma$ is reinforcement stress $\left(\mathrm{N} / \mathrm{mm}^{2}\right), E_{s}$ is reinforcement Young's modulus $\left(\mathrm{N} / \mathrm{mm}^{2}\right), \varepsilon$ is reinforcement strain, $f_{s}$ is reinforcement yield stress $\left(\mathrm{N} / \mathrm{mm}^{2}\right), f_{u}$ is reinforcement tensile strength $\left(\mathrm{N} / \mathrm{mm}^{2}\right)$, and $\varepsilon_{s h}$ is initial strain of strain hardening $(=1.5 \%)$.

\subsubsection{Steel-concrete interface}

The bond behavior of the reinforcement-concrete interface is subject to the effects of breathing, etc., and it is difficult to directly model it from the test results. Therefore in this research the concrete stress-strain 
model was used for the stress-strain relationship of the reinforcement-concrete interface. However, the tensile strength $f_{t}$ was reduced to $50 \%$. It was confirmed in past research that the pull-out behavior of deformed bar can be appropriately reproduced with this model (Hayashi et al. 2013).

\section{Result of the numerical analysis}

\subsection{Verification of the analytical model 5.1.1 Initial cracks}

Table 4 shows the maximum initial crack widths and the residual initial crack widths induced during preloading. As in the experiments, the maximum initial crack widths induced in the analysis were virtually the same as the target values. Also, although the analysis values of the residual initial crack widths during unloading were slightly large, the residual crack width in the presence of transverse reinforcement was increased, so the same trend as that of the experiments, was obtained (see M-1.0-B-T(2) and M-1.0-B-NT). It can be seen that the

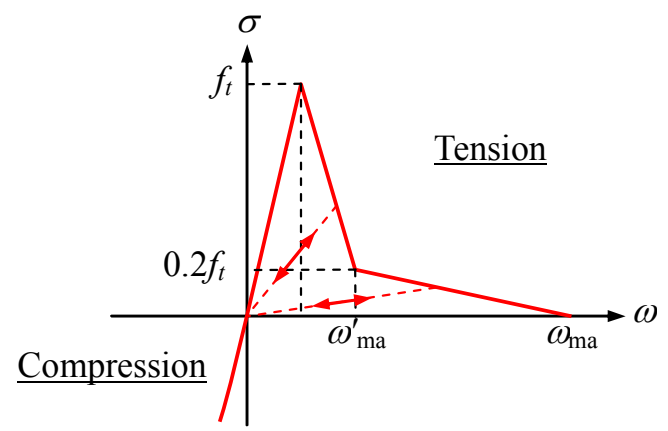

(a) Normal spring

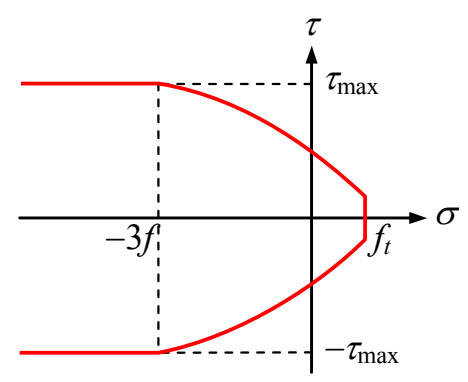

(c) Failure criterion effects of, the bond of the deformed bar, the crack opening behavior, and the transverse bar, on the crack closing behavior was reproduced well.

\subsubsection{Relationship between pull-out load and free end or anchorage end slip}

Figure 19 shows the relationship between the pull-out load and the free end or anchorage end slip obtained in the analysis. For comparison, the experimental results are also shown. The analysis results generally agree with the experiment, so it is considered that the effect of the presence and absence of the mechanical anchorage, the initial crack, and the transverse reinforcement has been appropriately reproduced. In addition, the pull-out load capacity values from Table $\mathbf{4}$ are also shown, and in all cases the difference from the experimental results was maintained to within the range of $10 \%$.

\subsubsection{Failure properties}

Figure 20 shows an example of the state of the model at failure obtained in the analysis. The analysis results of

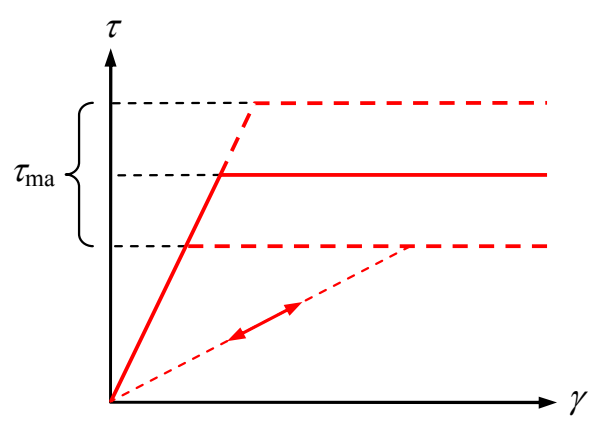

(b) Shear spring

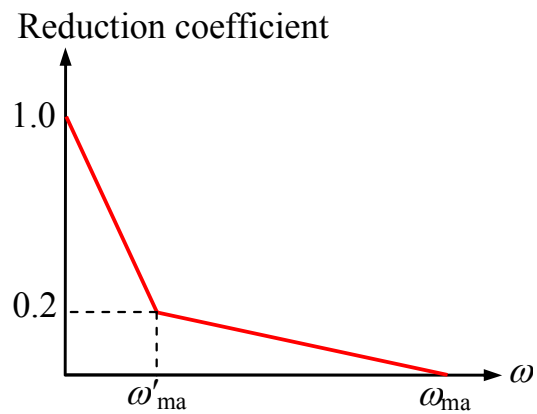

(d) Shear reduction model

Fig. 16 Constitutive models of concrete.

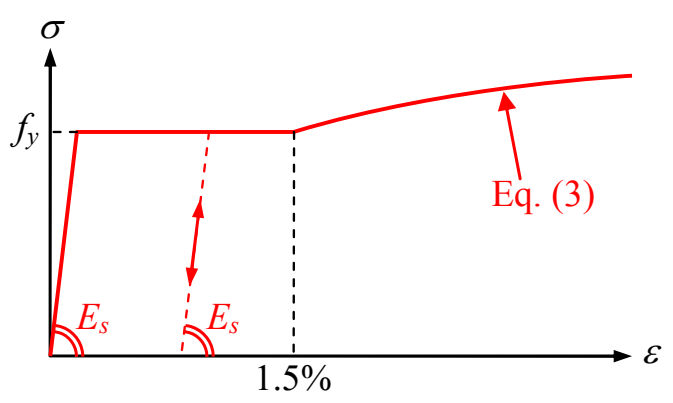

Fig. 17 Constitutive model of steel (normal spring).

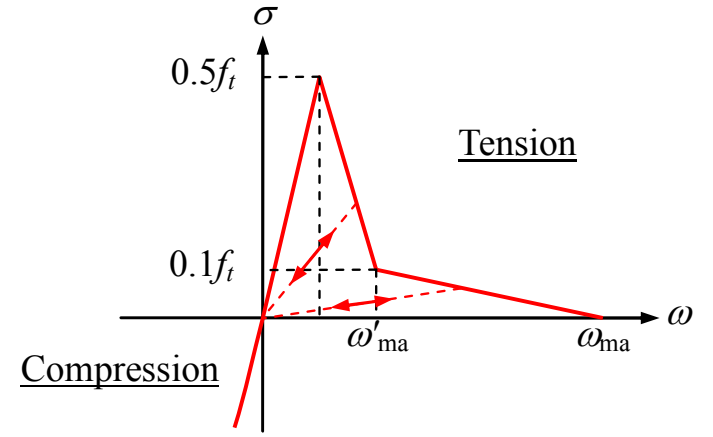

Fig. 18 Constitutive model of interface (normal spring). 
Figs. 20(a), (b) and (c) correspond to Figs. 8(a), (b) and (c) respectively. In the analysis, in the cases using a mechanical anchorage, cone cracking occurred in the cover concrete near the anchorage, resulting in ultimate failure. Also, in the cases where the initial crack was induced, it can be seen that the angle of the inclined cracks generated from the mechanical anchorage tended to be smaller. It is inferred that the bearing force in the off-axis direction of reinforcement generated from the anchorage, is reproduced.

\subsubsection{Strain distribution in the pull-out bar}

Figure 21 shows the changes in the strain distribution of the pull-out deformed bar, obtained from the analysis. For comparison, the experimental results are also shown. For both the experiment as well as analysis, the strains shown in the figure are the average values of the right side and the left side. There is a general agreement between the analysis results and the experiment results, hence the bond and slip behavior of the deformed bar associated with the increase in pull-out load was reproduced well.

From the above it has been confirmed that the pull-out behavior of deformed bars in RC with small cover can be reproduced well with this analysis model.

\subsection{Investigation of the mechanism of pull-out failure}

5.2.1 Effect of eliminating the bond on one side

Figure 22 shows the cracking pattern at the maximum load during preloading. As shown in Fig. 11, the phenomenon of forming the initial crack so that it passes
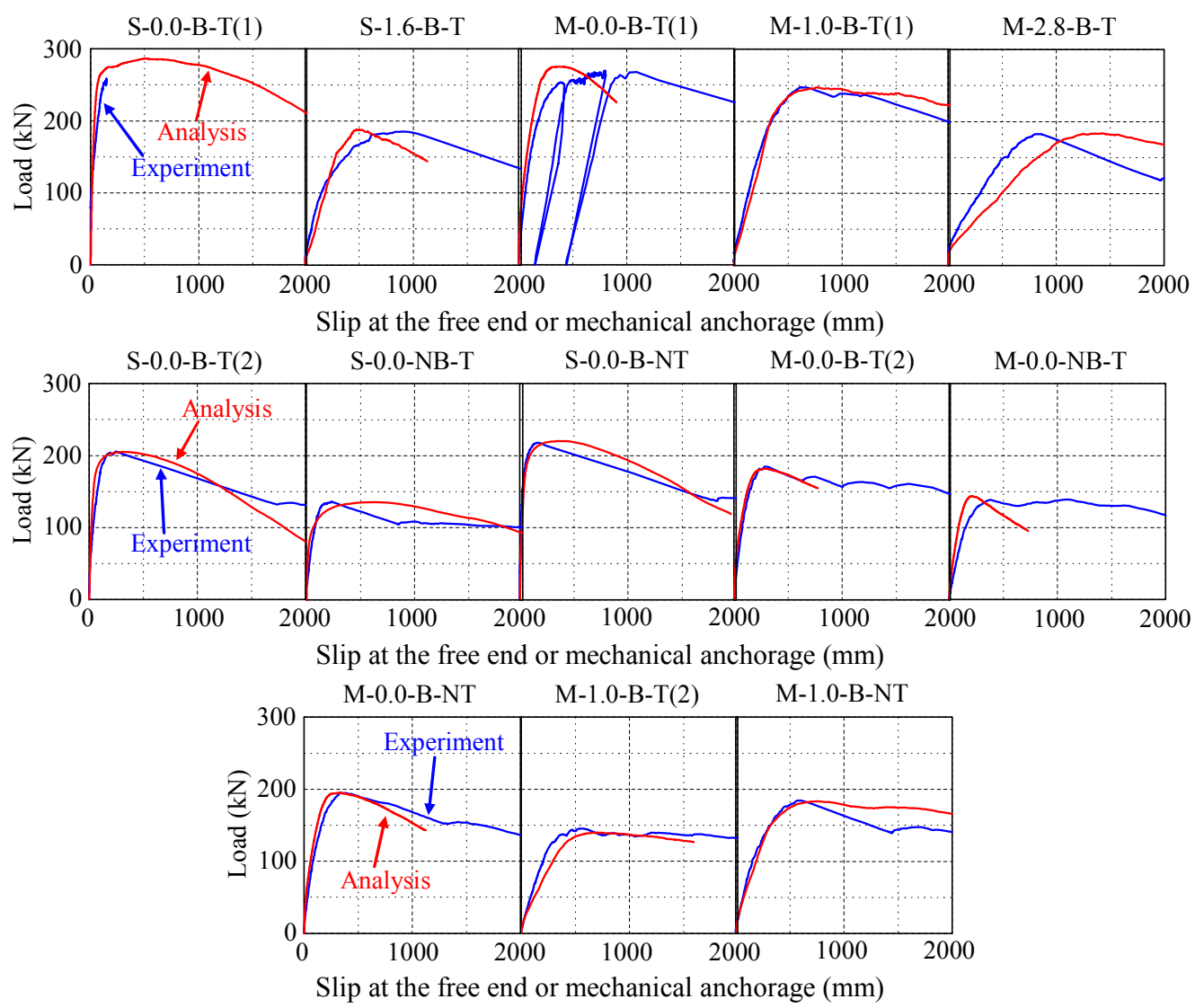

Fig. 19 Comparison of pull-out load-slip at the free end or anchorage relationships in the experiment and analysis.

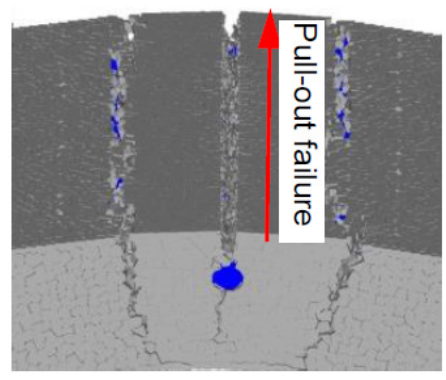

(a) S-1.6-B-T

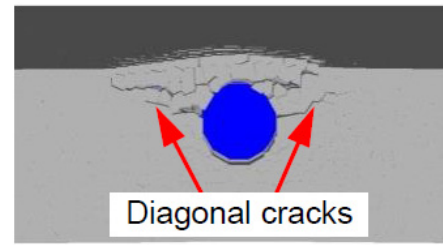

(b) M-0.0-B-T(1)

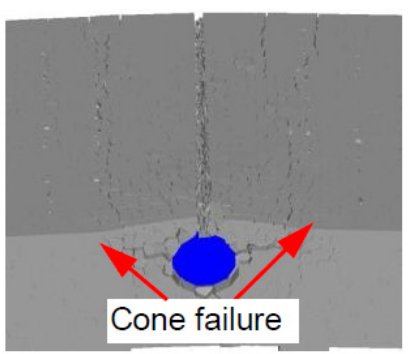

(c) M-1.0-B-T(1)

Fig. 20 Failure pattern in the analyses (deformation $\times 20$ ). 
around one side of the reinforcement has been reproduced in the analysis. In this analysis, the initial crack passed around the left side in S-1.6-B-T, and passed around the right side in M-1.0-B-T(1) and M-2.8-B-T.

Figure 23 shows the curvature distribution and de-

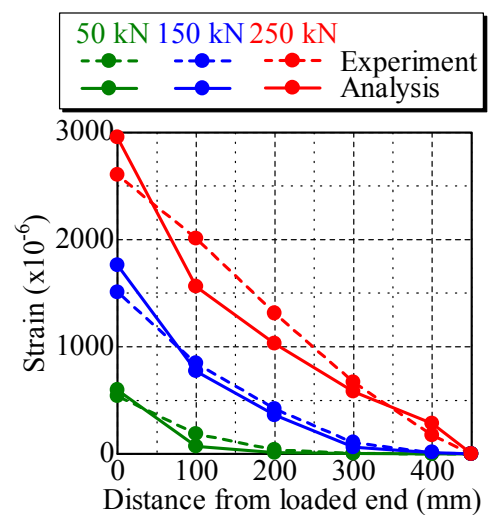

(a) S-0.0-B-T(1)

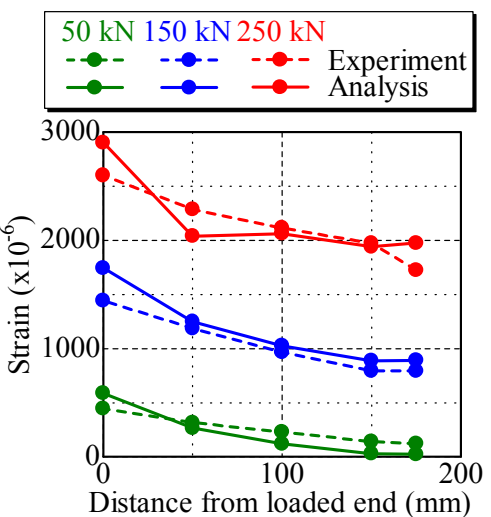

(c) $\mathrm{M}-0.0-\mathrm{B}-\mathrm{T}(1)$

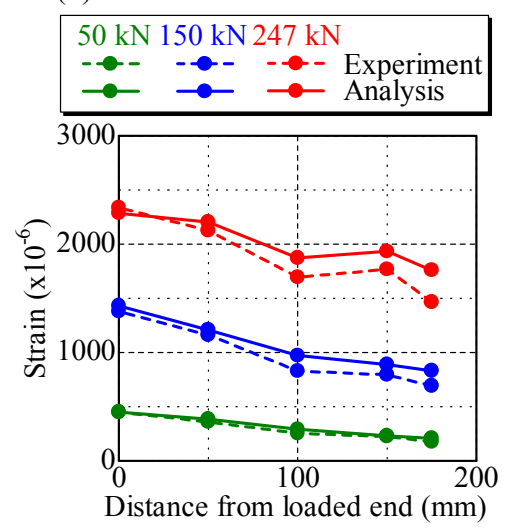

(d) M-1.0-B-T(1)

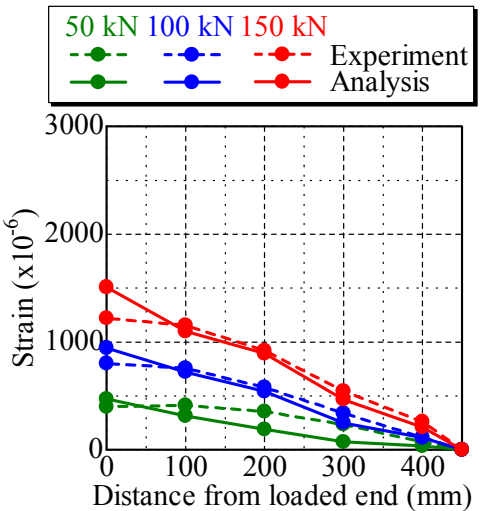

(b) S-1.6-B-T

Fig. 21 Comparison of strain distribution in the experiment and analysis.

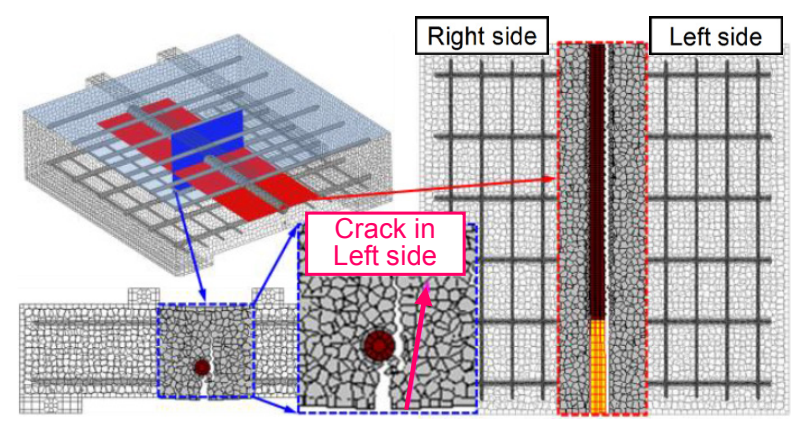

(a) S-1.6-B-T

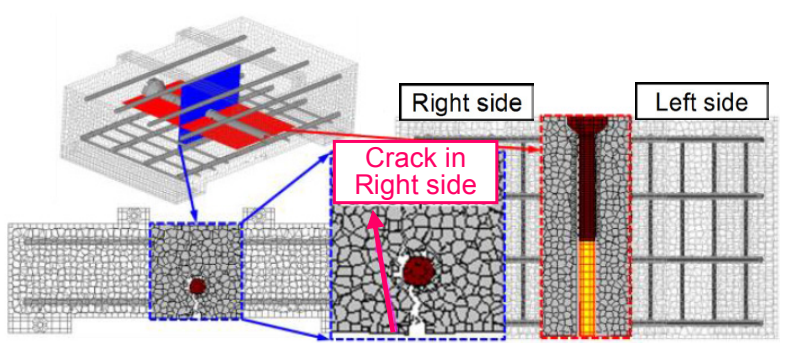

(b) M-1.0-B-T(1)

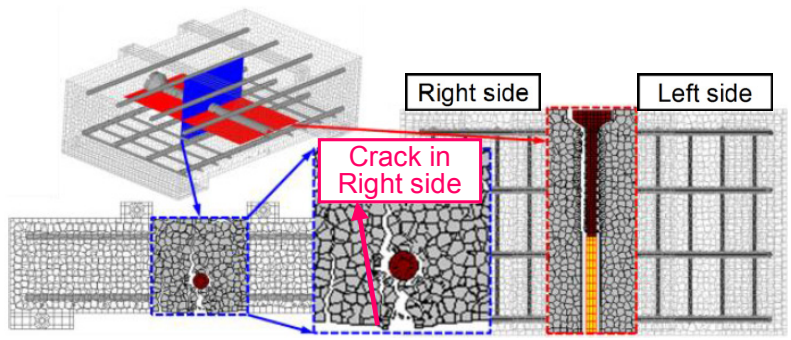

(c) M-2.8-B-T

Fig. 22 Pattern of initial crack in the analyses (deformation $\times 10$ ). 
is in tension, is taken to be the positive value. In the case of M-1.0-B-T(1) and M-2.8-B-T in which the initial crack passed around the right side, it can be seen that the curvature in the region near the loading point is positive, and in the region near the mechanical anchorage is negative. This is the same trend as the experimental result for M-0.0-NB-T which was unbonded on the left side as shown in Fig. 16. The deformed state exhibits a wave form shape corresponding to the curvature distribution. Near the anchorage the reinforcement is extended in the vertical direction in the figure, but below that it is curved to the left side, and near the loading point it is again extended in the vertical direction. It is considered that this is because the mechanical anchorage is behaving as a fixed point, as stated in Section 3.2.3.

By forming the initial crack, so that it passes around the reinforcement on one side as described above, a large curvature tends to be produced particularly near the mechanical anchorage, causing concern for over stress concentration problems, etc., when the fatigue loads are acting.

\subsubsection{Effect of transverse reinforcement}

Figure 24 shows the changes in the strain distribution of the transverse bar arranged near the mechanical an- chorage. It is to be noted that the strain shown in the figure is for an element in the center of the cross-section of the transverse bar. Since the strain induced by the bending load was significantly larger than that induced in the pull-out loading, those two strain distributions look almost the same in the figure. When the initial crack was induced by preloading, it can be seen that, the larger the maximum initial crack width, the greater the area over which, the strain in the transverse bar exceeds the yield strain. Figure 25 shows the deformed state of the transverse bar, provided near the mechanical anchorage at the maximum pull-out load. With M-0.0-B-T(1), in which the initial crack was not induced, the transverse bar deformed over a comparatively local range, and in contrast with M-1.0-B-T(1) and M-2.8-B-T in which the initial crack was induced, the transverse bar deformed over a comparatively wide range. This is to be considered because, during preloading the bond of the transverse bar was reduced. In particular with M-2.8-B-T, the strain at positions where the bending cracking did not occur, during preloading, also greatly exceeded the yield strain. Hence it is inferred that the bond failure was significant, and there is a high possibility of occurrence of bond cracking around the reinforcement. It is inferred that, since the thickness of the cover was comparatively small,

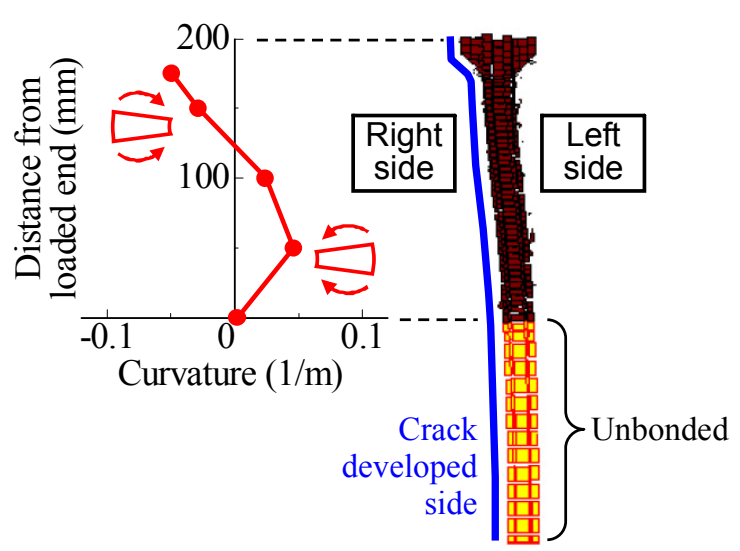

(a) M-1.0-B-T(1)

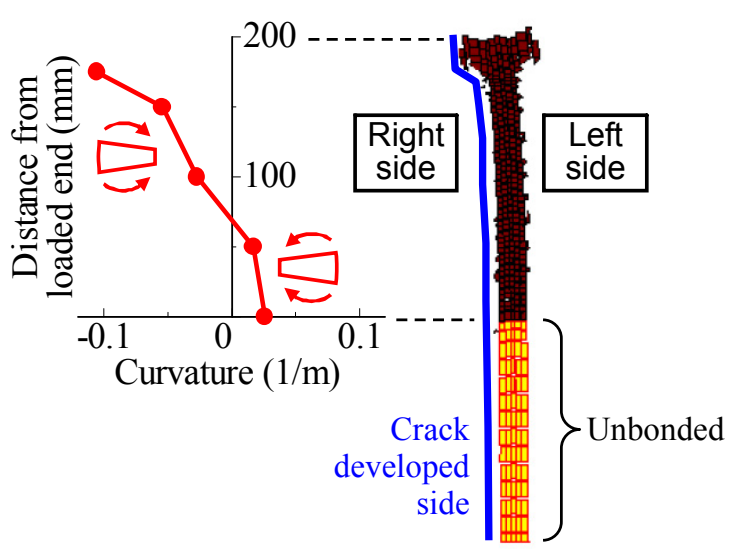

(b) M-2.8-B-T

Fig. 23 Curvature distribution and deformation of the pull-out steel bars with mechanical anchorage obtained in the analysis.

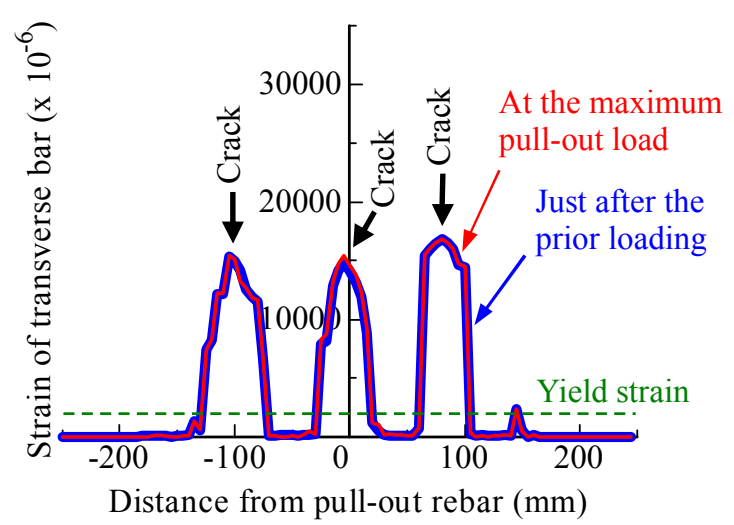

(a) M-1.0-B-T(1)

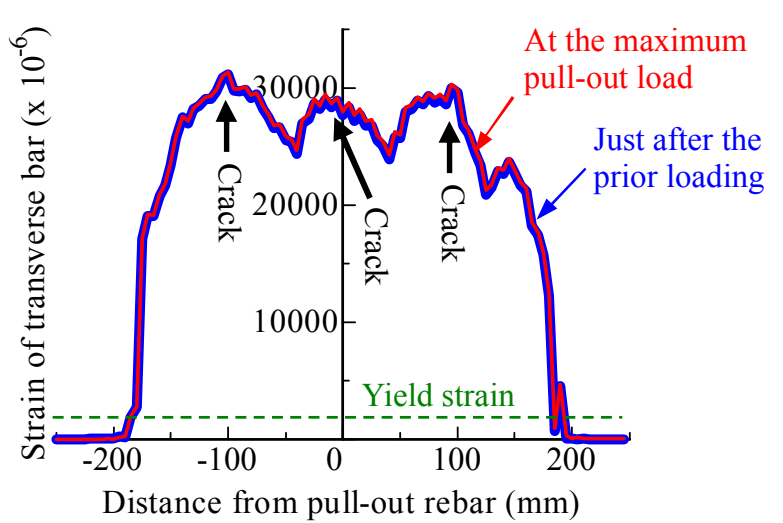

(b) M-2.8-B-T

Fig. 24 Change of strain distribution in transverse bar near the mechanical anchorage. 
while inducing the initial crack, the cover concrete was already in a state in which spalling could easily occur, due to the bearing stress from the knots in the off-axis direction of the reinforcement. The fact that a crack along the pull-out deformed bar is also seen in the cross-sectional view along the pull-out deformed bar in Fig. 25 indicates that the crack is formed on a plane surface. When the pull-out load was acting, a large bearing force acted on the concrete cover, particularly near the mechanical anchorage. One possible reason that can be considered is that the pull-out load capacity was reduced by the transverse reinforcement, particularly for the cases having the mechanical anchorage. Even though cover concrete was already in a state in which spalling could easily occur, the bond of the transverse bar seems to be still remaining according to the residual crack width shown in Table 4. Larger residual crack in the case with the transverse bar indicates that the remaining bond generates the restraint effect of the rebar on crack opening and closing.

The decrease of pull-out resistance due to the transverse reinforcement as described above is considered to be caused by the reduction of the constraint effect of the cover concrete due to bond failure of the transverse reinforcement, in addition to the increase in the residual initial crack width as described in Section 3.2.4.

\section{Conclusions}

In order to investigate the effect on the behavior of pull-out failure, of initial cracking along deformed bars in concrete, with comparatively small cover thickness, experiments and numerical analyses were carried out in the presence or absence of a mechanical anchorage, the initial crack width, the presence or absence of bond on one side of the deformed bar, and the presence or absence
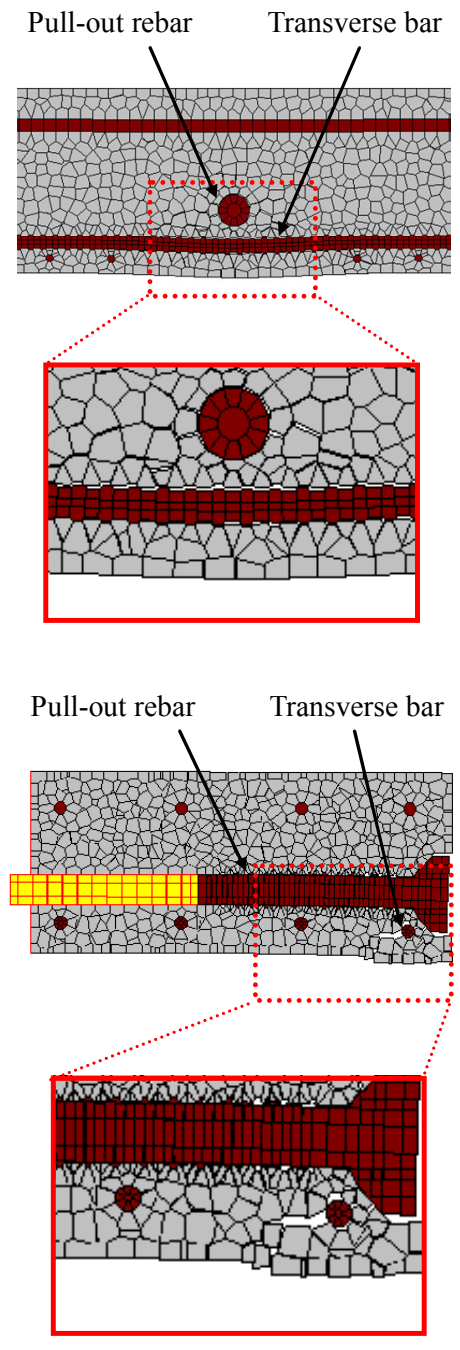

(a) M-0.0-B-T(1)

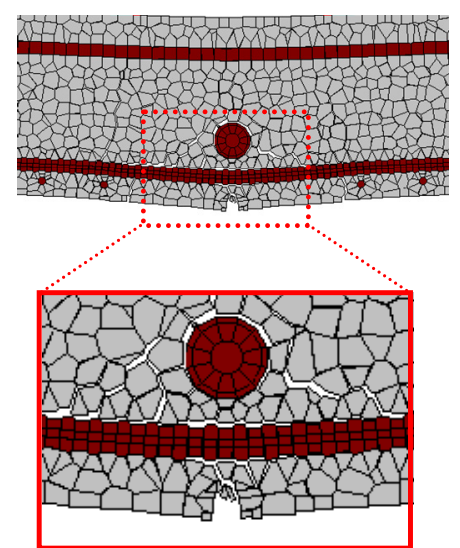

Cutting surface along the transverse bar
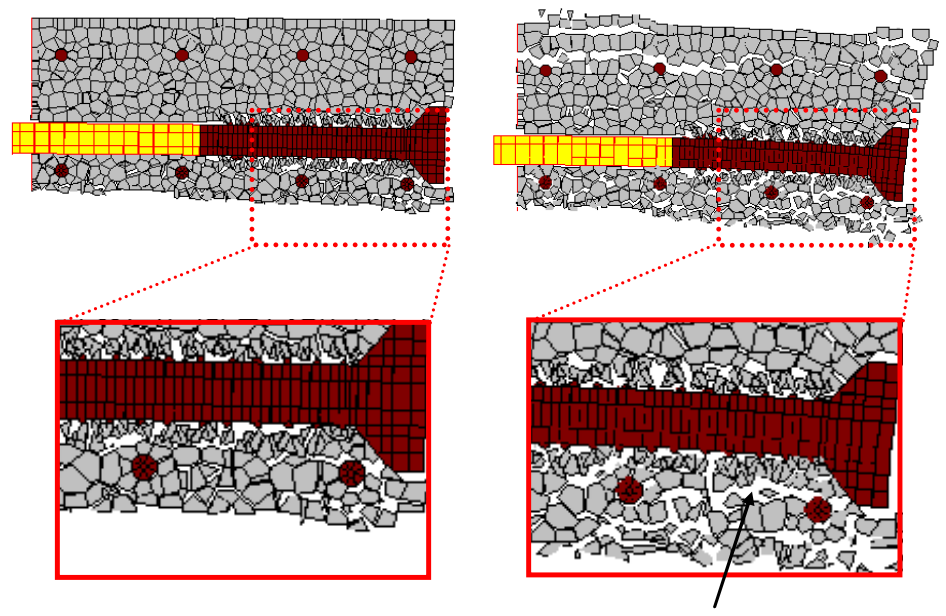

Spalling starts to occur.

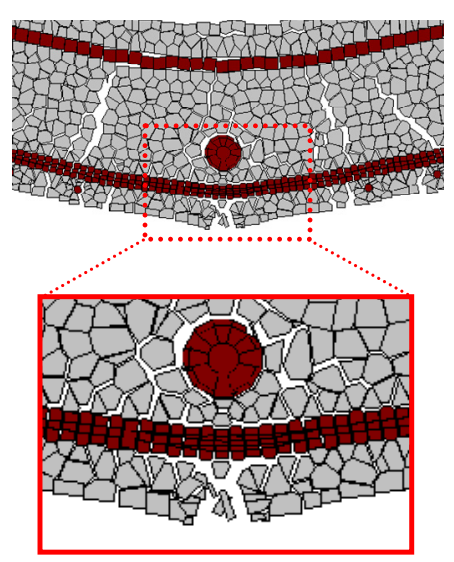

Cutting surface along the pull-out rebar

(b) M-1.0-B-T(1)

(c) M-2.8-B-T

Fig. 25 Deformation of transverse bar at the maximum pull-out load (deformation $\times 5$ ). 
of transverse reinforcement as parameters. The conclusions obtained from this research were as follows.

1) The 3-dimensional meso-scale discrete analysis using Rigid Body-Spring Model can reproduce the pull-out behavior of deformed bars with and without mechanical anchorages in cracked reinforced concrete. Crack patterns, deformation of the deformed bars, as well as the pull-out capacities and load-displacement relationships can be well predicted.

2) As the initial crack width is increased, the pull-out capacity of the deformed bars is reduced. However, this reduction in the pull-out capacity, due to initial cracking can be minimized slightly by the use of mechanical anchorages.

3) The initial cracking along the reinforcement is generated so that the crack passes around one side of the reinforcement. Therefore when the pull-out load is acting, the tensile stress generated within the cross-section of the reinforcement is not uniform. In particular when a mechanical anchorage is used, the anchorage is fixed in the rotational direction, and it behaves as a fixed end, so a large bending stress is generated near the anchorage.

4) For the same maximum value of initial crack width experienced previously, transverse reinforcement tends to reduce the pull-out load capacity of the deformed bars. This is to be considered because the residual value of the initial crack width is increased, and the concrete cover can easily spall due to yielding of the transverse reinforcement and the loss of bond.

\section{References}

Adachi, T., Kuramoto, H. and Matsui, T., (2011). "Stress transferring mechanism of exterior wide-beam to column joints using headed beam bars." Journal of Structural and Construction Engineering (AIJ), 76(663), 979-987. (in Japanese)

Chun, C. S., Lee, H. S., Kang, T. H. K., Oh, B. and Wallace, J. W., (2007). "Mechanical anchorage in exterior beam-column joints subjected to cyclic loading." ACI Structural Journal, 104(1), 102-113.

Delhomme, F., Roure, T., Arrieta, B. and Limam, A., (2015). "Static and cyclic pullout behavior of cast-in-place headed and bonded anchors with large embedment depths in cracked concrete." Nuclear Engineering and Design, 287, 139-150.

Goto, Y., (1971). "Cracks formed in concrete around deformed tension bars." ACI Journal, 68(4), 244-251.

Hayashi, D. and Nagai, K., (2013). "Meso-scale structural analysis of anchorage performance of RC with multi-layer steel reinforcements by three-dimensional discrete analysis method." Journal of JSCE,
69(2), 241-257. (in Japanese)

Japan Society of Civil Engineers, (2007). "Recommendations for design, fabrication and evaluation of anchorages and joints in reinforcing bars [2007]." Concrete Library, 126. (in Japanese)

Kawai, T., (1978). "New discrete models and their application to seismic response analysis of structure." Nuclear Engineering Design, 48, 207-229.

Lee, H. J. and Yu, S. Y., (2009). "Cyclic response of exterior beam-column joints with different anchorage methods." ACI Structural Journal, 106(3), 329-339.

Murakami, M., Fuji, T. and Kubota, T., (1997). "Evaluation of mechanical anchorage capacities of main bars in beam-column joints based on pull-out tests." Journal of Concrete Engineering (JCI), 8(2), 1-10. (in Japanese)

Nagai, K., Sato, Y. and Ueda, T., (2004). "Mesoscopic simulation of failure of mortar and concrete by $3 \mathrm{D}$ RBSM." Journal of Advanced Concrete Technology, 3(3), 385-402.

Oomori, S. and Uchida, Y., (2009). "Investigation on side splitting failure of mechanical anchorages." Proceedings of $64^{\text {th }}$ JSCE Annual Meeting, V, 987-988. (in Japanese)

Nakazawa, H., Sakaguchi, N. and Asai, M., (2002). "Headed anchorage capacities of beam reinforcement bars in reinforced concrete beam-column joints based on the pull-out tests." Journal of Structural and Construction Engineering (AIJ), 558, 173-180. (in Japanese)

Orangun, C. O., Jirsa, J. O. and Been, J. E., (1977). “A reevaluation of test data on development length and splices." Journal of ACI, 74(3), 114-122.

Shima, H., Chou, L. L. and Okamura, H., (1987). "Micro and macro models for bond in reinforced concrete." Journal of the Faculty of Engineering, The University of Tokyo (B), XXXIX(2), 133-194.

Tadokoro, T., Tanimura, Y., Tokunaga, M. and Yoneda, D., (2009). "Static tensile characteristics of mechanical anchorages at joints in viaduct." Proceedings of Japan Concrete Institute, 31(2), 691-696. (in Japanese)

Takeyama, T., Tanaka, M., Tanaka, S., and Uchida, Y., (2008). "Anchorage performance evaluation test by using Mechanical Anchorages." Proceedings of Japan Concrete Institute, 30(3), 697-702. (in Japanese)

Yoshitake, K., Ogura, D. and Ogawa, K., (2011). "Effect of anchorage types of main bars in beams on the structural performances of beam-column joints." Proceedings of 66th JSCE Annual Meeting, V-47, 947-948. (in Japanese) 